\title{
Las agendas territoriales españolas: análisis temático de los debates en las elecciones autonómicas del año 2019
}

\section{The Spanish territorial agendas: a thematic analysis of the debates in the regional elections of the year 2019}

Paulo Carlos López-López. Universidad de Santiago de Compostela. España.

paulocarlos.lopez@usc.es

$[\underline{\mathrm{CV}}](\mathrm{C}$

Palmira Chavero Ramírez. Facultad Latinoamericana de Ciencias Sociales (FLACSO). Ecuador. pchavero@,flacso.edu.ec

$[\underline{\mathrm{CV}}]$ (1) $\mathrm{G}$

María Pereira López. Universidad de Santiago de Compostela. España. maria.pereira.lopez@usc.es

$[\underline{\mathrm{CV}}]$ (C)

Los resultados de este artículo forman parte de los trabajos del Equipo de Investigaciones Políticas de la Universidad de Santiago de Compostela (GI-1161), así como del proyecto DEBATv, Debates Electorales Televisados en España: Modelos, Proceso, Diagnostico y Propuesta (CSO2017-83159-R), proyecto de I+D $+I$ (Retos) financiado por el Ministerio de Economía, Industria y Competitividad (Mineco) y la Agencia Estatal de Investigación (AEI) del Gobierno de España, con el apoyo del Fondo Europeo de Desarrollo Regional (Feder) de la Unión Europea (UE).

Cómo citar este artículo / Referencia normalizada

López-López, P. C., Chavero Ramírez, P. y Pereira López, M. (2020). Las agendas territoriales españolas: análisis temático de los debates en las elecciones autonómicas del año 2019. Revista Latina de Comunicación Social, (76), 163-188. https:/www.doi.org/10.4185/RLCS-2020-1442

\section{RESUMEN}

Introducción: La presente investigación analiza temáticamente los debates electorales televisados celebrados en las distintas Comunidades Autónomas de España que en el año 2019 celebraron comicios. Metodología: Codificación y agregación a través de una puntuación de los temas expresados por cada candidato, determinados por la estructura del debate realizado en cada televisión. Presentación en tablas y aplicación del coeficiente de correlación de Spearman para medir niveles de correlación. Resultados: Los issues crónicos (política económica, servicios públicos y empleo) ocupan las primeras posiciones en rango en la mayor parte de las Comunidades Autónomas, sumándosele el de "Ideología y campaña", propio de los contextos electorales. Discusión y conclusiones: La presencia de partidos políticos nacionalistas o regionalistas en el gobierno tiende a generar problemas compartidos entre sus respectivos territorios.

PALABRAS CLAVE: comunicación política; agenda setting; televisión; debates electorales; elecciones autonómicas; ciencia política. 


\begin{abstract}
Introduction: This research thematically analyzes the televised electoral debates held in the different Autonomous Communities of Spain that held elections in 2019. Methodology: Coding and aggregation through a score of the topics expressed by each candidate, determined by the structure of the debate on each television. Table presentation and application of Spearman's correlation coefficient to measure correlation levels. Results: The chronic issues (economic policy, public services, and employment) occupy the first positions in rank in most of the Autonomous Communities, adding the one of "Ideology and campaign", typical of electoral contexts. Discussion and conclusions: The presence of nationalist or regionalist political parties in the government tends to generate shared problems between their respective territories.
\end{abstract}

KEYWORDS: political communication; agenda-setting; television; electoral debates; regional elections; political science.

\title{
CONTENIDOS
}

1. Introducción. 1.1. La relación entre las agendas mediática, política y pública. 1.2 El estudio de las campañas y los debates electorales. 1.3 Los debates electorales en España. 2. Materiales y métodos. 3. Resultados. 3.1. Elecciones en Asturias y Cantabria. 3.2. Elecciones en Navarra y La Rioja. 3.3 Elecciones en Aragón y Valencia. 3.4. Elecciones en Murcia y Extremadura. 3.5. Elecciones en Castilla León y Castilla La Mancha. 3.6. Elecciones en Baleares y Canarias. 3.7. Elecciones en Madrid. 3.8. Viejos temas y nuevas discusiones: análisis y correlaciones. 4. Conclusiones y discusión. 5. Referencias bibliográficas.

\section{Introducción}

El domingo 26 de mayo de 2019 tuvieron lugar las elecciones municipales, europeas y autonómicas en España, con un resultado que situaba al Partido Socialista Obrero Español como principal fuerza en el ámbito estatal de cara a un nuevo período electoral. El presente artículo toma como referencia los comicios regionales celebrados en Aragón, Asturias, Islas Baleares, Canarias, Cantabria, CastillaLa Mancha, Castilla y León, Comunidad Valenciana, Extremadura, La Rioja, Madrid, Murcia y Navarra para el análisis temático de los debates electorales. Debido a la multiplicidad de soportes utilizados para dichos debates, se seleccionaron aquellos con formato televisivo, priorizándose los realizados en las televisiones autonómicas y, en la medida de lo posible, aquellos en los que participaron los partidos políticos que establece la legalidad vigente por resolución de las Juntas Electorales.

La campaña electoral es el período de mayor intensidad en el ejercicio político, por cuanto la disputa política se exacerba a medida que se acerca el momento de alcanzar el poder. En ese contexto, los debates electorales se han consolidado a lo largo de los años como uno de los momentos principales de esa disputa (McKinney, \& Carlin, 2004), en el que se ponen en marcha estrategias y mecanismos desde los actores políticos y mediáticos. En el marco de las campañas electorales y del proceso de decisión de voto, uno de los elementos fundamentales es la manera en que los candidatos políticos se posicionan con respecto a los temas de debate, de tal manera que la evaluación que el ciudadano realiza de ese posicionamiento acaba convirtiéndose en uno de los factores para la configuración de la decisión electoral. En ese sentido, en campaña se activan las asociaciones que realizan los ciudadanos de los candidatos electorales con respecto a los temas de interés, entre los cuales están tanto issues estructurales como aquellos otros de naturaleza coyuntural y particular de un territorio específico. 


\subsection{La relación entre las agendas mediática, política y pública}

Atendiendo a la teoría clásica del establecimiento de la agenda (McCombs, \& Shaw, 1972), diremos que los medios de comunicación tienen la capacidad de transferir la relevancia de los temas que consideran más importantes (agenda mediática) a la ciudadanía, de manera tal que los temas que los medios posicionan como importantes acaban siendo considerados como importantes para el electorado (agenda pública). Para entender esta relación, conviene partir del propio concepto de agenda, entendido como el conjunto de temas o issues que los medios de comunicación proponen como importantes y, en consecuencia, son visibilizados en la esfera mediática (Weaver, 1997), siendo issue el "problema social, a menudo conflictivo, que ha recibido cobertura" (Dearing, \& Rogers, 1996, p. 3). Así como los medios construyen su propia agenda, los actores políticos tienen asimismo un repertorio de temas a los que les conceden mayor importancia, por lo que centran su atención en ellos, tanto para destacarlos como problemas como para ofrecer una posible solución a ellos.

Esta relación entre las distintas agendas es uno de los pilares más importantes a la hora de estudiar cómo se configura la opinión pública (McCombs, 2018), pero es particularmente importante en clave electoral. Aquí, la interacción entre las distintas agendas mencionadas, a la que habría que añadir la agenda personal, puede llegar a incidir en la configuración de la decisión electoral (Bouza, \& González, 2009) mutado por la irrupción de la sociedad digital, de consumos en segundas pantallas y por las redes sociales (Yang et. al., 2016), aunque esencialmente manteniendo esquemas de construcción de la agenda muy semejantes (Harder, Sevemans, \& Van Aelst, 2017; López-López, \& Vásquez González, 2018; López-López, \& Oñate, 2019).

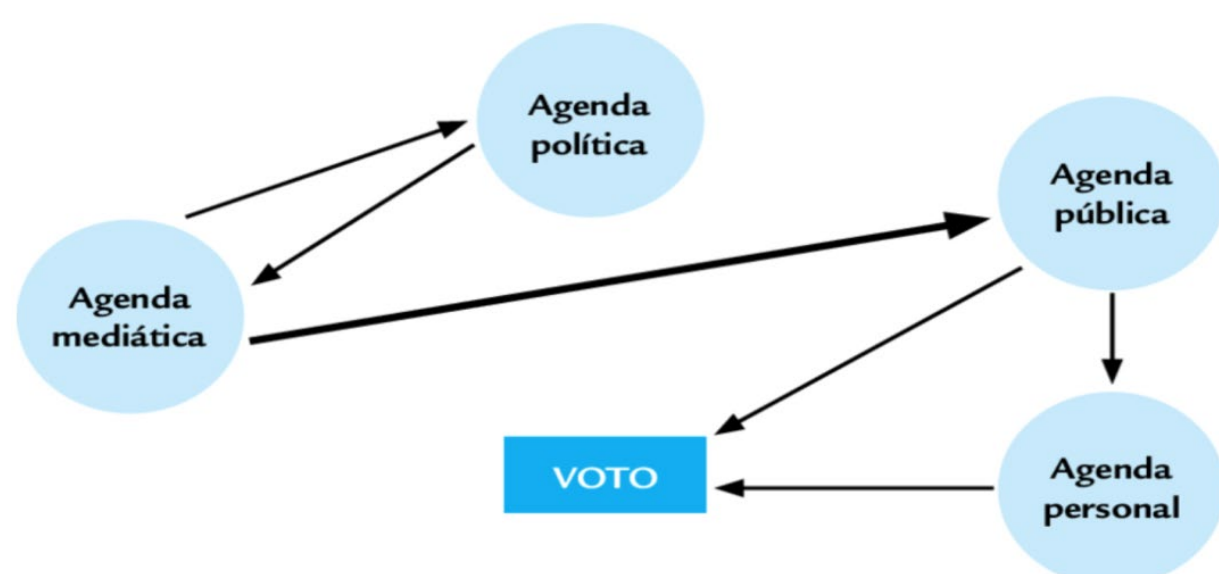

Imagen 1. Decisión de voto.

Fuente: Bouza \& González, 2009.

\subsection{El estudio de las campañas y los debates electorales}

La literatura académica arroja abundante evidencia empírica en el estudio de la campaña electoral y los debates (Barreiro Rivas, Pereira López, \& García Hípola, 2015; Herranz-Rubio, 2019), que se divide en general en distintas áreas: el desarrollo de la propia campaña, su cobertura por parte de los medios de comunicación y los efectos que genera en la decisión de voto de la ciudadanía (García Marín, 2015). En el marco de una campaña electoral, el debate entre los candidatos se reconoce como el punto álgido de la disputa por el voto, premisa que se mantiene por varias razones. En primer lugar, es el momento en el que los candidatos tienen la oportunidad de debatir entre ellos sobre sus propuestas programáticas $\mathrm{y}$, en los últimos tiempos, incluso de poder recibir las preguntas o los comentarios de los propios ciudadanos. En segundo lugar, el debate electoral supone un momento de relativo control por parte de 
los candidatos con respecto a los medios de comunicación, pues es el acto de la campaña electoral en el que los candidatos se pueden dirigir a los ciudadanos evadiendo la intermediación de los medios de comunicación, aunque a través de ellos (López-García et. al, 2018). En tercer lugar, el debate electoral es el momento de la campaña al que más atención le prestan los propios medios de comunicación, tanto en la preparación como en su desarrollo y análisis posterior. No en vano, los medios son un actor cada vez más importante en la aceptación y negociación de la manera en que se celebra el debate. Por último, estos suelen tener altos niveles de audiencia, constituyéndose probablemente en el acto que concentra al mayor número de ciudadanos, con nuevos modelos de consumo en segundas pantallas (Saavedra-Llamas, \& Rodríguez- Fernández, 2018). Por otro lado, el debate electoral puede considerarse el momento de máxima expresión de la personalización de la política, por cuanto durante su desarrollo se exaltan las habilidades políticas de cada candidato. Asimismo, es el momento en el que se manifiestan las alianzas y en el que se ponen en marcha estrategias de ataque y conflicto como principales herramientas al servicio del negativismo (González, \& Chavero, 2013), en este caso del negativismo político (Mayer, 1996; Iyengar, 1991).

\subsection{Los debates electorales en España}

La tradición de celebrar debates electorales en período de campaña comienza en Estados Unidos con el primer debate televisado en $1952 \mathrm{y}$, de manera progresiva, se ha ido generalizando en el resto de los países de tradición democrática como una expresión de la voluntad política de diálogo y acercamiento al ciudadano. A medida que su uso se ha ido extendiendo, los debates electorales se han ido convirtiendo en actos cada vez más sofisticados, pasando del formato plano que tenían en los inicios a uno más dinámico que observamos en los últimos años, con la participación incluso a través de las redes sociales. Si bien los candidatos pueden, en los debates electorales, dirigirse a sus potenciales votantes sin la intermediación de los medios de comunicación, no es menos cierto que, cada vez más, la negociación de los detalles que implican la realización de un debate electoral pasa por criterios más relacionados con el formato mediático, especialmente televisivo, que con el campo político en sí mismo, a pesar de que tiene que existir una confianza mutua entre actores (Campo Vidal, 2017). De hecho, los medios de comunicación llegan incluso a poner sus propias condiciones en la negociación previa a la celebración del debate electoral. Se ve así, en última instancia, la expresión máxima de democracias centradas en los medios, tal y como sugería Swanson (1995).

En el caso español, la tradición de debate electoral es menos extensa, aunque también profundamente estudiada (Herranz-Rubio, 2019; Reguera, \& Rodal, 2018). Uno de los más célebres fue el que protagonizaron Felipe González y José María Aznar en 1993; después, no fue sino hasta 2008 cuando se retoman con José Luis Rodríguez Zapatero (PSOE) y Mariano Rajoy (PP), quienes inauguran una segunda etapa de debates electorales, tras el cual se vienen sucediendo de manera generalizada en las distintas citas. La generalización de los debates ha sido tal que se realizan en las campañas de distintos niveles: nacional y autonómico, lo que refleja el peso dado a la principal actividad de la campaña.

En general, la mayoría de la literatura sobre campañas electorales y, en específico, sobre los debates electorales en el caso español, abordan este fenómeno desde la perspectiva de su recepción por parte de la audiencia; no obstante, encontramos algunos estudios para el caso español que hacen énfasis en el estudio de los temas de campaña y su efecto en el individuo, en los que se aporta evidencia empírica sobre la escasa influencia de la publicidad electoral en los temas de campaña, en especial en relación a la influencia de los medios a la hora de posicionar estos temas (Humanes, \& Moreno, 2012); también encontramos algunos estudios sobre los efectos inmediatos de los debates electorales (García Luengo, 2011) y otros sobre la manera en que los medios cubren los debates electorales en el caso español, sobre todo desde la teoría del framing (García Marín, 2015). Por último, algunos 
trabajos abordan la significativa influencia de los debates electorales a la hora de tomar la decisión electoral, en especial en contextos electorales reñidos (Lledó, 2001).

La importancia de la agenda temática es especialmente significativa en campaña electoral por la atención que presta la audiencia a los temas de debate y por la asociación con la publicidad política (Jamieson, \& Campbell, 1994; López Escobar et al., 1996), período en el que también se acrecienta la importancia de la imagen de los candidatos. El énfasis en los temas de debate durante la campaña electoral no sólo es importante para la configuración de la opinión pública y los temas de discusión, sino incluso para la decisión de voto (Weaver, 1997; Bouza, \& González, 2009).

\section{Materiales y métodos}

La investigación de los debates electorales en el marco epistemológico de la teoría de agenda setting cuenta con un amplio número de trabajos en las últimas décadas, muy especialmente a través de la técnica del análisis de contenido (Pérez Curiel, \& Lancharro Montiel, 2017) mediante su tematización (López-López, et.al, 2019), encuadre (Téllez Morales, 2009) o determinando la influencia de la estructura sobre la agenda (Benoit, \& Hansen, 2001). Por ello, la metodología del presente trabajo queda ampliamente justificada, en la que se analizan temáticamente los debates electorales que tuvieron como marco la celebración de los comicios autonómicos de mayo de 2019 en España, en Aragón, Asturias, Islas Baleares, Canarias, Cantabria, Castilla-La Mancha, Castilla y León, Comunidad Valenciana, Extremadura, La Rioja, Madrid, Murcia y Navarra. Se seleccionaron aquellos con formato televisivo en los entes autonómicos, a excepción del caso cántabro, en el que se ha analizado el del Diario El Montañés como formato más próximo al resto. A tal fin, la técnica utilizada fue la del análisis de contenido a través de un minutado de cada uno de los debates. En cada uno de los grandes bloques (agenda mediática) se realizó un proceso de codificación y agregación de las temáticas concretas de cada uno de los candidatos (agenda política) con su correspondiente ponderación (primaria, secundaria, terciaria), puntuados con un $1,0.5$ y 0.25 respectivamente. Esta puntuación se ha realizado en función de la importancia y del énfasis que ha puesto cada candidato en sus propuestas, analizando las réplicas realizadas por los adversarios y sus contrarréplicas como mecanismo de ajuste de la importancia de cada tema. El resultado de la suma de las sucesivas intervenciones de cada uno de ellos conforma la agenda temática del debate electoral. Este modelo de análisis es una adaptación de la llamada "área de impacto" (Bouza, 2004), ampliamente contrastada en investigaciones precedentes.

El objetivo principal (OP) de la presente investigación es comparar las agendas de los debates electorales autonómicos celebrados en el año 2019 en España, siendo los objetivos secundarios dos: a) situar en rango la posición de los llamados problemas crónicos (o1); b) conocer la inclusión del feminismo, del medio ambiente y de la inmigración en las agendas territoriales (o2). Debido a la naturaleza de la investigación, se trabaja con cuatro preguntas de investigación: ¿Sigue estando presente la corrupción como un tema predominante? (P1) ¿Es el debate puramente ideológico el que construye la tematización? (P2) ¿El discurso de la extrema derecha incide en la configuración de la agenda? (P3) ¿Ha estado presente Cataluña en los debates? (P4).

Para responder a estas preguntas de investigación, proponemos dos hipótesis que guían el presente trabajo son dos:

- Los factores económicos y de proximidad determinan la correlación entre las agendas territoriales (H1).

- El partido en el gobierno modifica la configuración de la agenda en los debates electorales $(\mathrm{H} 2)$. 
RLCS, Revista Latina de Comunicación Social, 76, 163-188

[Investigación] DOI: 10.4185/RLCS-2020-1442 | ISSN 1138-5820 | Año 2020

En la siguiente tabla (1) se puede observar un resumen de todos los debates electorales de las elecciones autonómicas de 2019 en España que han sido analizados para este trabajo.

Tabla 1. Debates analizados.

\begin{tabular}{|c|c|c|c|}
\hline Comunidad Autónoma & Fecha y lugar & Participantes & Duración \\
\hline Asturias & $\begin{array}{l}20 \text { de mayo de } 2019 \\
\text { (RTPA) }\end{array}$ & $\begin{array}{l}\text { Adrián Barbón (PSOE); Teresa Mallada (PP); } \\
\text { Lorena Gil (Podemos); Ángela Vallina (IU); } \\
\text { Carmen Moriyón (Foro); Juan Vázquez } \\
\text { (Ciudadanos); Ignacio Blanco (Vox). }\end{array}$ & 145 minutos \\
\hline Cantabria & $\begin{array}{l}15 \text { de mayo de } 2019 \text { (El } \\
\text { Diario el Montañés) }\end{array}$ & $\begin{array}{l}\text { María José Sáenz de Buruaga (PP); Miguel } \\
\text { Ángel Revilla (PRC); Pablo Zuloaga (PSOE); } \\
\text { Félix Álvarez (Ciudadanos); Cristóbal Palacio } \\
\text { (Vox); Mónica Rodero (Podemos) }\end{array}$ & 97 minutos \\
\hline Navarra & $\begin{array}{l}22 \text { de mayo (Navarra } \\
\text { TV) }\end{array}$ & $\begin{array}{l}\text { Javier Esparza (Navarra Suma); María Chivite } \\
\text { (PSN-PSOE); Uxue Barkos (Geroa Bai); } \\
\text { Bakartxo Ruiz (EH Bildu); Mikel Buil } \\
\text { (Podemos); María Luisa de Simón (Izquierda- } \\
\text { Ezkerra). }\end{array}$ & 105 minutos \\
\hline La Rioja & $\begin{array}{l}16 \text { de mayo de } 2019 \\
\text { (TVR) }\end{array}$ & $\begin{array}{l}\text { José I. Ceniceros (PP); Concha Andreu } \\
\text { (PSOE), Raquel Romero (Unidas Podemos); } \\
\text { Pablo Baena (Ciudadanos); Julio Revuelta } \\
\text { (Partido Riojano). }\end{array}$ & 103 minutos \\
\hline Aragón & $\begin{array}{l}14 \text { de mayo de } 2019 \\
\text { (Aragón TV) }^{1}\end{array}$ & $\begin{array}{l}\text { Luis María Beamonte (PP); Javier Lambán } \\
\text { (PSOE); Maru Díaz (Podemos-Equo); Daniel } \\
\text { Pérez Calvo (Ciudadanos); Arturo Aliaga } \\
\text { (PAR); José Luis Soro (CHA); Álvaro Sanz } \\
\text { (IU); Santiago Morón (Vox) }\end{array}$ & 122 minutos \\
\hline Valencia & $\begin{array}{l}17 \text { de abril de } 2019 \\
\text { (delegación territorial } \\
\text { RTVE) }\end{array}$ & $\begin{array}{l}\text { Rubén Dalmau (Unides Podem-EU), Toni } \\
\text { Cantó (Ciudadanos), Mónica Oltra } \\
\text { (Compromís), Ximo Puig (PSPV-PSOE) e } \\
\text { Isabel Bonig del PP-CV. }\end{array}$ & 100 minutos \\
\hline Murcia & $\begin{array}{l}17 \text { de mayo (Televisión } \\
\text { Región de Murcia) }\end{array}$ & $\begin{array}{l}\text { Fernando López (PP); Diego Conesa (PSOE); } \\
\text { Óscar Urralburu (Podemos); Isabel Franco } \\
\text { (Ciudadanos). }\end{array}$ & 123 minutos \\
\hline Extremadura & $\begin{array}{l}21 \text { de mayo (Canal } \\
\text { Extremadura) }\end{array}$ & $\begin{array}{l}\text { Guillermo Fernández Vara (PSOE); José. A } \\
\text { Monago (PP); Irene de Miguel (Unidas por } \\
\text { Extremadura); Cayetano Polo (Ciudadanos); } \\
\text { Ju. Morales (Vox); Pedro Lanzas (Extremadura } \\
\text { Unida); Laura Márquez (Actúa) }\end{array}$ & 148 minutos \\
\hline Madrid & $\begin{array}{l}19 \text { de mayo de } 2019 \\
\text { (Telemadrid) }\end{array}$ & $\begin{array}{l}\text { Isabel Díaz Ayuso (PP); Ángel Gabilondo } \\
\text { (PSOE) Isabel Serra (Unidas Podemos); } \\
\text { Ignacio Aguado (Ciudadanos); Rocío } \\
\text { Monasterio (Vox). }\end{array}$ & 107 minutos \\
\hline Castilla León & $\begin{array}{l}14 \text { de mayo (Radio } \\
\text { Televisión de Castilla } \\
\text { León) }\end{array}$ & $\begin{array}{l}\text { Alfonso Fernández Mañueco (PP), Luis } \\
\text { Tudanca (PSOE), Pablo Fernández (Podemos) } \\
\text { y Francisco Igea (Cs). }\end{array}$ & 108 minutos \\
\hline Castilla La Mancha & $\begin{array}{l}20 \text { de mayo (Castilla La } \\
\text { Mancha Media) }\end{array}$ & $\begin{array}{l}\text { Emiliano García-Page (PSOE); Paco Núñez } \\
\text { (PP), José García Molina (Podemos); Carmen } \\
\text { Picazo (Ciudadanos); Daniel Arias (Vox) }\end{array}$ & 134 minutos \\
\hline
\end{tabular}

\footnotetext{
${ }^{1}$ El debate no se encuentra en repositorios públicos. Fue cedido para fines exclusivamente investigadores por la dirección de Aragón TV
} 
RLCS, Revista Latina de Comunicación Social, 76, 163-188

[Investigación] DOI: 10.4185/RLCS-2020-1442 | ISSN 1138-5820 | Año 2020

\begin{tabular}{|c|c|c|c|}
\hline Baleares & 15 de mayo (IB3) & $\begin{array}{l}\text { Gabriel Company (Partido Popular); Francina } \\
\text { Armengol (PSOE); Juan Pedro Yllanes } \\
\text { (Unidas Podemos); Marc Pérez-Ribas } \\
\text { (Ciudadanos); Miquel Ensenyat (Més); Jaume } \\
\text { Font (El Pi); Silvia Tur (Gent per Formentera); } \\
\text { Josep Castells (Més per Menorca) }\end{array}$ & 147 minutos \\
\hline Canarias & 23 de mayo de 2019 & $\begin{array}{l}\text { Fernando Clavijo (Coalición Canaria); Ángel } \\
\text { Torres (PSOE); Asier Gómez (PP); Noemí } \\
\text { Santana (Si Podemos Canarias); Román } \\
\text { Rodríguez (NC); Vidina Espino Ramírez } \\
\text { (Ciudadanos) }\end{array}$ & 93 minutos \\
\hline
\end{tabular}

Fuente: elaboración propia.

Los resultados se presentan a través de tablas, aplicando el coeficiente de correlación de Spearman para medir el grado de correlación entre la agenda ordenada de temas de cada Comunidad Autónoma en función de su peso. En caso de empate entre dos o más temas, se sitúa primero el que en más ocasiones ha estado en rango superior; de persistir el empate, se revisa el minutado y se coloca el que más tiempo ha estado presente en pantalla. Se han seleccionado 18 issues por ser los que más presentes han estado en todos y cada uno de los debates, excluyendo los que no se repiten o lo hacen con menos intensidad. Los temas son los siguientes: empleo, política económica, medio ambiente, corrupción y regeneración, servicios públicos, ideología y campaña, política social y derechos ciudadanos, política estatal, infraestructura y transporte, igualdad, PYMES, política institucional, financiación autonómica, sector primario, colectivos minorizados, vivienda, política territorial e industria y energía. Igualmente, el análisis de la correlación bivariada se realiza comparando la dimensión territorial, económica (riqueza, pobreza y desempleo), poblacional (densidad y envejecimiento) e institucional (partidos de gobierno), por entenderlo como factores explicativos.

\section{Resultados}

\subsection{Elecciones en Asturias y Cantabria}

El principal debate electoral a la Presidencia del Principado de Asturias, con más de dos horas de duración, se celebró el lunes 20 de mayo en la Radiotelevisión pública asturiana y en él participaron siete candidatos: Adrián Barbón (PSOE); Teresa Mallada (PP); Lorena Gil (Podemos); Ángela Vallina (IU); Carmen Moriyón (Foro); Juan Vázquez (Ciudadanos) e Ignacio Blanco (Vox). El resultado de los comicios arrojó una clara victoria del PSOE (20 escaños) que, sumados a los diputados de Izquierda Unida (2), le permitió acceder a la presidencia al candidato socialista en segunda votación. El desarrollo del debate se realizaría sobre cinco grandes bloques (Industria; Infraestructuras, movilidad y área metropolitana; Medio rural y despoblación; Cultura, cooficialidad y reforma del Estatuto de Autonomía; Servicios públicos), en donde cada candidato tendría tres minutos, además de una pequeña presentación al inicio en la que se indicaría la primera medida a llevar a cabo, y una última intervención general de un minuto apelando al voto.

En el ámbito temático el debate estuvo acotado por los bloques estipulados por la corporación pública en acuerdo con los partidos políticos, dejando poco margen para la introducción de nuevos issues por parte de los candidatos. El socialista Barbón y el candidato de Ciudadanos, Juan Vázquez, fueron los más interpelados (este último como consecuencia de ejercer un cargo de asesor del anterior gobierno), asumiendo el liberal varios encuadres negativos, incluso, por parte de Partido Popular y Vox, lo que promovería un bajo potencial de coalición. En los primeros lugares en rango se encuentran los llamados problemas crónicos, ligados a la política económica (1), a la institucionalidad (3) y a la situación de los 
servicios públicos (2), situándose la corrupción en quinto lugar (tema recurrente en época de crisis) y la industria como elemento regional de carácter diferenciador (carbón y transición energética). Una de las características de Cantabria es que no cuenta con un servicio de radiodifusión propio, por lo que el debate electoral relevante a las elecciones al Parlamento (con formato televisivo) que se ha seleccionado para el presente estudio fue el realizado por El Diario El Montañés, uno de los más relevantes en la zona. En él participaron los principales candidatos a la Presidencia de la región: María José Sáenz de Buruaga (PP); Miguel Ángel Revilla (PRC); Pablo Zuloaga (PSOE); Félix Álvarez (Ciudadanos); Cristóbal Palacio (Vox) y Mónica Rodero (Podemos). El resultado arrojaría una victoria del regionalista, que alcanzaría la Presidencia con el apoyo del PSOE.

Tabla 2. Agendas temáticas Asturias y Cantabria.

\begin{tabular}{|c|c|c|c|c|c|}
\hline \multicolumn{3}{|c|}{ ASTURIAS } & \multicolumn{3}{|c|}{ CANTABRIA } \\
\hline Rango & Tema & Puntuación & Rango & Tema & Puntuación \\
\hline 1 & Política económica & 7,50 & 1 & Servicios públicos & 12,50 \\
\hline 2 & Servicios públicos & 7,25 & 2 & Infraestructuras y transporte & 9,75 \\
\hline 3 & Política institucional & 6,75 & 3 & Política económica & 8,75 \\
\hline 4 & Campaña e ideología & 6,25 & 4 & Campaña e ideología & 7,25 \\
\hline 5 & Corrupción y regeneración & 5,75 & 5 & Empleo & 6,75 \\
\hline 6 & Infraestructuras y transporte & 5,5 & 6 & Política institucional & 6,25 \\
\hline 7 & Empleo & 5 & 7 & Industria y energía & 5 \\
\hline 8 & Industria y energía & 4,75 & 8 & $\begin{array}{l}\text { Política social y derechos } \\
\text { ciudadanos }\end{array}$ & 3,75 \\
\hline 9 & Cultura y lengua & 4,50 & 9 & Política estatal & 3,25 \\
\hline 10 & Medio Ambiente & 4,25 & 10 & Corrupción y regeneración & 2,25 \\
\hline 11 & Política territorial & 2,75 & 11 & Política territorial & 2 \\
\hline 12 & $\mathrm{I}+\mathrm{D}+\mathrm{i}$ & 2,50 & 12 & Igualdad & 1,75 \\
\hline 13 & Colectivos minorizados & 2,5 & 13 & Financiación autonómica & 1 \\
\hline 14 & $\begin{array}{l}\text { Política social y derechos } \\
\text { ciudadanos }\end{array}$ & 2,25 & 14 & PYMES & 1 \\
\hline 15 & Política estatal & 2,25 & 15 & Colectivos minorizados & 1 \\
\hline 16 & Vivienda & 1,50 & 16 & $\mathrm{I}+\mathrm{D}+\mathrm{i}$ & 0,75 \\
\hline 17 & Inmigración & 1,50 & 17 & Vivienda & 0,5 \\
\hline 18 & Sector primario & 1,25 & 18 & Sector primario & 0,25 \\
\hline 19 & PYMES & 0,75 & 19 & - & - \\
\hline 20 & Igualdad & 0,5 & 20 & - & - \\
\hline 21 & Otros & 0,5 & 21 & - & - \\
\hline
\end{tabular}

Fuente: elaboración propia.

El debate se realizó sobre seis bloques, con un minuto inicial y final (Balance de la legislatura; Infraestructuras; Servicios públicos; Empleo y economía; Educación; Pacto), con una estructura de 45 segundos iniciales por cada candidato y posteriormente flexibilidad en los tiempos dentro de lo establecido para cada bloque -con cierta medida- en las réplicas. Este formato permitió una confrontación dialéctica más viva y una confrontación de ideas más directa, además de obligar a los candidatos y a las candidatas a clarificar, inicialmente, sus propuestas. En general, el peso de las críticas y quién determinó la agenda fue Miguel Ángel Revilla, capaz de delimitar los subtemas tratados, desplazando al PP y C'S, omitiendo a Vox y con cierto reparto de papeles con el PSOE a la hora defender la gestión del gobierno anterior. La relación de temas presentados, en cuanto a rango, presentes los crónicos en primeros lugares (servicios públicos, infraestructuras, política económica y empleo), con el recurrente sobre campaña electoral (apelaciones personales, partidarias e ideológicas), situándose la corrupción (10) y la financiación autonómica (13) en posiciones subsidiarias, con la igualdad en un marginal duodécimo puesto (solo reivindicado por el PSOE) y ninguna apelación al medio ambiente. 


\subsection{Elecciones en Navarra y La Rioja}

El debate electoral de las elecciones al Parlamento de Navarra se celebró en la corporación privada Navarra TV el día 22 de mayo, contando con los candidatos y candidatas presidenciales de los principales partidos en liza: Javier Esparza (Navarra Suma), María Chivite (PSN-PSOE), Uxue Barkos (Geroa Bai), Bakartxo Ruiz (EH Bildu), Mikel Buil (Podemos) y María Luisa de Simón (Izquierda-Ezkerra). Su estructura ha sido muy característica ya que no han existido bloques cerrados, sino preguntas orientativas sobre ciertos temas que permitían un mayor dinamismo de los segmentos. Además del primer minuto genérico (¿Qué se juega Navarra los próximos años?) y de la intervención final, se han tratado cuestiones relativas a la fiscalidad, servicios públicos, autogobierno e infraestructuras con turnos de tres minutos y medio. En lo que se refiere a la codificación del tema "Financiación autonómica" (4), se ha realizado a partir de las menciones dentro del issue "Política económica" (2) o "Política territorial" (5) que se refería a la foralidad. Desde un punto de vista cualitativo el debate ha estado fuertemente polarizado y con claro componente autorreferencial (codificado bajo el tema "Ideología y campaña"), con graves acusaciones entre Navarra Suma y el resto de los contendientes. La coalición conservadora apeló constantemente a la estabilidad que representa ante "nacionalistas y populistas" interpelando a la candidata socialista. Como característica diferenciadora del resto de debates, ha estado muy presente la referencia al PNV y al País Vasco, además de una suerte de "agenda oculta" de Geroa Bai y EH Bildu. En lo que se refiere a la agenda de temas, los tres primeros en rango asumen una dimensión crónica sin un carácter excepcional, conjugando la ideología, la economía y los servicios públicos. Es importante resaltar las nulas referencias a la corrupción o a la inmigración, además de la baja posición en rango del tema "Igualdad" o "Medio Ambiente", en las posiciones 10 y 11 respectivamente.

Tabla 3. Agendas temáticas Navarra y La Rioja.

\begin{tabular}{|l|l|l|l|l|l|}
\hline \multicolumn{2}{|c|}{ Nema } & Puntuación & \multicolumn{2}{c|}{ Rango } & \multicolumn{2}{c|}{ Tema } & Puntuación \\
\hline Rango & \multicolumn{1}{|c|}{ Tema } \\
\hline 1 & Ideología y campaña & 9 & 1 & Servicios públicos & 9 \\
\hline 2 & Política económica & 7,5 & 2 & Política económica & 7 \\
\hline 3 & Servicios públicos & 6,75 & 3 & Ideología y campaña & 5,5 \\
\hline 4 & Financiación autonómica & 5 & 4 & Infraestructuras y transporte & 5 \\
\hline 5 & Política territorial & 4 & 5 & Empleo & 4 \\
\hline 6 & Empleo & 3,75 & 6 & Población y territorio & 3 \\
\hline 7 & $\begin{array}{l}\text { Política social y derechos } \\
\text { ciudadanos }\end{array}$ & 3,5 & 7 & Industria y energía & 2,5 \\
\hline 8 & Infraestructuras y transporte & 2,5 & 8 & Política institucional & 2,25 \\
\hline 9 & Política institucional & 2 & 9 & Sector primario & 1,75 \\
\hline 10 & Igualdad & 2 & 10 & $\begin{array}{l}\text { Política social y derechos } \\
\text { ciudadanos }\end{array}$ & 1,50 \\
\hline 11 & Medio ambiente & 1,75 & 11 & Igualdad & 1,50 \\
\hline 12 & Política estatal & 1,50 & 12 & Política territorial & 1,25 \\
\hline 13 & Vivienda & 1,25 & 13 & Medio ambiente & 1,25 \\
\hline 14 & Cultura y lengua & 1,25 & 14 & Política estatal & 1 \\
\hline 15 & I+D+i & 0,75 & 15 & PYMES & 0,75 \\
\hline 16 & Industria y energía & 0,5 & 16 & Colectivos minorizados & 0,75 \\
\hline 17 & Corrupción y regeneración & 0,25 & 17 & Corrupción y regeneración & 0,75 \\
\hline 18 & - & - & 18 & Financiación autonómica & 0,25 \\
\hline 19 & - & - & 19 & I+D+i & 0,25 \\
\hline 20 & - & - & 20 & Otros & 0,25 \\
\hline
\end{tabular}

Fuente: elaboración propia. 
El debate electoral de las elecciones al Parlamento de la Rioja se celebró el 16 de mayo en Televisión Rioja (TVR), canal privado que pertenece al grupo Vocento, participando cinco de los seis candidatos invitados (Vox declinó participar): José Ignacio Ceniceros (PP), Concha Andreu (PSOE), Raquel Romero (Unidas Podemos), Pablo Baena (Ciudadanos) y Julio Revuelta (Partido Riojano). El debate se organizó sobre cuatro bloques de carácter genérico (Infraestructuras; Economía; Sanidad, Educación y Política social; Despoblación y medio rural) con intervenciones de tres minutos, con un minuto inicial y el llamado "minuto de oro". En general, los candidatos mantuvieron un discurso muy acorde con el de sus partidos políticos en otras contiendas: los populares apelaron a la política económica; Ciudadanos (más allá de los eslóganes de campaña, comunes en todas las comunidades autónomas), hablaron de libertad para elegir en el ámbito educativo y en eliminar los "chiringuitos" de la Administración; la coalición Podemos-Izquierda Unida-Equo hizo gala de su posición "morada" (igualdad) y "verde" (medio ambiente); los socialistas reforzaron todo lo que tiene que ver con los servicios públicos y el Partido Riojano hizo hincapié en su autonomía para "reforzar el autogobierno" de la región. La política estatal estuvo prácticamente ausente (14), con ciertas alusiones al gobierno de Pedro Sánchez, al igual que a la financiación autonómica (19). Los tres issues más recurrentes en la agenda temática son aquellos crónicos dentro de una campaña electoral: servicios públicos, política económica y los que tienen un marcado carácter autorreferencial (alusiones personales del candidato, apelación al propio partido o referencia ideológica). La principal característica de este debate electoral tiene que ver con su poco carácter específico, más allá del problema de las infraestructuras (4), la despoblación (6) o el sector primario (9). Las elecciones las ganaría la candidata socialista, que sería investida presidenta con el apoyo de Podemos e Izquierda Unida.

\subsection{Elecciones en Aragón y Valencia}

El día 14 de mayo tuvo lugar en la televisión pública Aragón TV el debate a las Cortes de Aragón con la participación de Luis María Beamonte (PP), Javier Lambán (PSOE, a la postre ganador e investido presidente), Maru Díaz (Podemos-Equo), Daniel Pérez Calvo (Ciudadanos), Arturo Aliaga (PAR), José Luis Soro (CHA), Álvaro Sanz (IU) y Santiago Morón (Vox). El debate, en la misma línea que el resto, estuvo dividido en cuatro grandes bloques ("Economía, Industria y Empleo"; "Derechos sociales"; "Aragón en España: autogobierno"; "El Aragón del futuro"), con dos y minutos y medio por candidato, además de un minuto de intervención inicial y el llamado minuto de oro final.

Tabla 4. Agendas temáticas Aragón y Valencia.

\begin{tabular}{|l|l|l|l|l|l|}
\hline \multicolumn{2}{|c|}{ Tema } & Puntuación & \multicolumn{1}{c|}{ Rango } & \multicolumn{1}{c|}{ Tema } & Puntuación \\
\hline Rango & \multicolumn{1}{|c|}{ Tén } & \multicolumn{1}{c|}{ Ideología y campaña } & 11,25 \\
\hline 1 & Servicios públicos & 12,75 & 1 & Corrupción y regeneración & 6,25 \\
\hline 2 & Ideología y campaña & 11,75 & 2 & Política económica & 5,5 \\
\hline 3 & Política económica & 11,50 & 3 & Empleo & 4,75 \\
\hline 4 & Política territorial & 9 & 4 & Igualdad & 4,75 \\
\hline 5 & Empleo & 6,5 & 5 & Financiación autonómica & 4,25 \\
\hline 6 & Igualdad & 4,5 & 6 & Servicios públicos & 4 \\
\hline 7 & Población y territorio & 4,25 & 7 & Política social y derechos & 3,25 \\
\hline 8 & Política social y derechos & 3 & 8 & Política territorial & 3 \\
\hline 9 & Política estatal & 3 & 9 & Política institucional & 2,5 \\
\hline 10 & Política institucional & 1,75 & 10 & Infraestructuras y transporte & 1,5 \\
\hline 11 & Infraestructuras y transporte & 1,75 & 11 & Medio Ambiente & 1,5 \\
\hline 12 & Medio ambiente & 1,50 & 12 & Política estatal & 1,25 \\
\hline 13 & Financiación autonómica & 1,50 & 13 & I+D+i & 1,25 \\
\hline 14 & Corrupción y regeneración & 1,25 & 14 & & \\
\hline
\end{tabular}


RLCS, Revista Latina de Comunicación Social, 76, 163-188

[Investigación] DOI: 10.4185/RLCS-2020-1442 | ISSN 1138-5820 | Año 2020

\begin{tabular}{|l|l|l|l|l|l|}
\hline \hline 15 & Sector primario & 1,25 & 15 & PYMES & 1,25 \\
\hline 16 & Industria y energía & 1 & 16 & Vivienda & 0,5 \\
\hline 17 & Cultura y lengua & 0,75 & 17 & Sector primario & 0,25 \\
\hline 18 & Vivienda & 0,75 & 18 & - & - \\
\hline 19 & PYMES & 0,75 & 19 & - & - \\
\hline 20 & I+D + i & 0,5 & 20 & - & - \\
\hline 21 & Colectivos minorizados & 0,25 & 21 & - & - \\
\hline
\end{tabular}

Fuente: elaboración propia.

Además de la clara distinción entre los bloques de izquierda y derecha, con los intentos de PAR y Ciudadanos de ejercer el rol de bisagra a través de la centralidad, también ha estado presente, más allá del autogobierno y de la política territorial, la situación de Catalunya. Por su proximidad geográfica y política, tanto PP como C's asumieron este cleavage como fundamental en su discurso, llegando a acusar a la Chunta Aragonesista, con la pasividad del PSOE, de llevar a cabo una política pancatalanista. Esto sirvió para reforzar el issue de política estatal (9) y territorial (4), con apelaciones a Pedro Sánchez y a Miquel Iceta por parte de Ciudadanos y llamamientos a la unidad de España por parte de PP y de Vox. Fueron estos últimos los que, sin éxito, asumieron el discurso de "la libertad" de elección del centro educativo (1) en defensa de los concertados. Los candidatos de la izquierda hicieron gala del carácter público de sanidad y educación, además de la reivindicación de la política social. Igualmente, el tema de campaña, la política económica y el empleo, han estado presentes en las primeras posiciones en rango, situándose en los últimos lugares la vivienda, el $\mathrm{I}+\mathrm{D}+\mathrm{i}$ o las pequeñas y medianas empresas.

La delegación territorial de Radio Televisión Española (RTVE) fue la encargada de organizar el debate con los principales candidatos a presidir la Generalitat Valenciana, que se celebró el 17 de abril de 2019 y en el que participaron Rubén Dalmau (Unides Podem-EU), Toni Cantó (Ciudadanos), Mónica Oltra (Compromís), Ximo Puig (PSPV-PSOE) e Isabel Bonig del PP-CV. El resultado electoral arrojaría una victoria del PSOE que haría de nuevo presidente al candidato socialista, con el apoyo de Compromìs y Unides Podem-EU. Con una duración de unos 100 minutos, se estructuró de una forma clásica: entre el minuto inicial y el minuto de oro, cinco bloques temáticos ("Economía"; "Sanidad y Educación", "Política de igualdad y conciliación", "Transparencia, confianza y pactos"; "Financiación autonómica") en el que cada contendiente tendría tres minutos para fijar su posición y debatir. En general, el debate estuvo caracterizado por un fuerte componente ideológico: por una parte, los firmantes del Acord del Botànic; por el otro, una entente entre PP y C's, con muy pocos ataques entre ellos y construyendo un relato conjunto en el que el ítem principal nace de la necesidad urgente de cambio. Ante la "imposición" de "la coalición sanchista de izquierda", el bloque conservador asume "la bandera liberal", consagrada en temas como la libertad de los padres de escoger la lengua y el colegio en el cual educar a sus hijos o la bajada generalizada de impuestos. Por el otro, tanto Puig como Oltra ponen en valor la "estabilidad institucional" y los avances en materia social, de igualdad o de empleo que consiguió su gobierno. Como temas excepcionales en este debate, en comparación con el resto, se encuentra la segunda posición que ocupa la corrupción y regeneración, derivado del gran número de casos ocurridos en la comunidad en la época del Partido Popular y que aún tienen gran cabida en la agenda política; y la financiación autonómica, al ser la valenciana una de las comunidades más perjudicadas por el sistema de financiación vigente.

\subsection{Elecciones en Murcia y Extremadura}

Canal Extremadura fue el lugar escogido para la celebración del debate electoral con los principales candidatos a la presidencia de la Región, que enfrentó al popular Fernando López Miras; Diego Conesa del PSOE; de Podemos, Óscar Urralburu y de Ciudadanos la candidata Isabel Franco. El 
debate ha seguido el formato clásico de cuatro grandes bloques con un minuto de intervención inicial y otro final solicitando el voto, aunque la denominación de éstos ha sido lo suficientemente amplia como para permitir introducir las prioridades de los partidos ("Política económica"; "Agua y medio ambiente"; "Modelo de región"; "Pactos y regeneración democrática"). Las estrategias del PSOE y Podemos han sido la de proponer un gobierno alternativo a través de una coalición progresista, con presencia sostenida de la defensa de los servicios públicos (5) y de la política social (7); la del PP ha consistido en la generación de marcos negativos a Ciudadanos para que aclarara su política de pactos (6).

La agenda temática ha sido muy particular, situándose el empleo en primera posición en rango; en segundo término, la política económica y el medio ambiente en tercer lugar. Este último no ha estado centrado en el cambio climático, sino en la situación del Mar Menor y en las políticas públicas hídricas (trasvase Tajo-Segura), muy presente en las últimas décadas en la política murciana. Como otro issue distintivo y con una presencia sostenida en las intervenciones de C's, PSOE y Podemos se encuentra la corrupción, principalmente por la forma de llegar a la presidencia por parte del candidato del PP tras la dimisión de Pedro Antonio Sánchez López tras su imputación. Por el lado contrario, han tenido muy baja visibilidad la industria, la vivienda o el autogobierno, en las últimas posiciones en rango. Las elecciones han convertido a Fernando López Miras en presidente, con el apoyo, en tercera sesión de investidura, de Ciudadanos y de la ultraderechista Vox.

Canal Extremadura fue el lugar escogido para la celebración del debate electoral con los principales candidatos a la Presidencia de esta Comunidad. Bajo el lema "Extremadura Decide" el 21 de mayo se enfrentaron Guillermo Fernández Vara, del PSOE; José Antonio Monago, del PP; Irene de Miguel, de Unidas por Extremadura (Podemos); Cayetano Polo, de Ciudadanos; Juan Antonio Morales, de Vox; Pedro Lanzas, de Extremadura Unida, y Laura Márquez, del partido Actúa, fundando por Gaspar Llamazares y Baltasar Garzón. La estructura se ha diferenciado notablemente de los anteriores debido a su flexibilidad: a los cuatro grandes bloques en los que cada candidato tiene dos minutos ("Economía", "Sociedad", "Calidad de vida" y "Grandes desafíos"), se le suman cuatro turnos de preguntas por parte de periodistas, una sección de debate de carácter libre y un minuto final solicitando el voto.

Tabla 5. Agendas temáticas Murcia y Extremadura.

\begin{tabular}{|l|l|l|l|l|l|}
\hline \multicolumn{2}{|c|}{ Tema } & Puntuación & \multicolumn{1}{c|}{ Rango } & \multicolumn{1}{c|}{ Tema } & Puntuación \\
\hline Rango & \multicolumn{1}{|c|}{ TemTREMADURA } & 18 \\
\hline 1 & Empleo & 8,75 & 1 & Ideología y campaña & 11,75 \\
\hline 2 & Política económica & 4,25 & 2 & Empleo & 10 \\
\hline 3 & Medio ambiente & 4 & 3 & Servicios públicos & Política económica \\
\hline 4 & Corrupción y regeneración & 3,75 & 4 & Territorio y población & 6,75 \\
\hline 5 & Servicios públicos & 3,75 & 5 & Política institucional & 5,25 \\
\hline 6 & Ideología y campaña & 3,75 & 6 & Sector primario & 5,25 \\
\hline 7 & $\begin{array}{l}\text { Política social y derechos } \\
\text { ciudadanos }\end{array}$ & 3,5 & 7 & Infraestructuras y transporte & 4,50 \\
\hline 8 & Política estatal & 2,75 & 8 & Igualdad & 4,25 \\
\hline 9 & Infraestructura y transporte & 1,25 & 9 & Política territorial & 4,25 \\
\hline 10 & Igualdad & 1,25 & 10 & Corrupción y regeneración & 3,50 \\
\hline 11 & PYMES & 1,25 & 11 & Colectivos minorizados & 3,25 \\
\hline 12 & Política institucional & 0,75 & 12 & Medio ambiente & 3 \\
\hline 13 & Financiación autonómica & 0,50 & 13 & Turismo & 3 \\
\hline 14 & Sector primario & 0,50 & 14 & Industria y energía & 2,75 \\
\hline 15 & Colectivos minorizados & 0,25 & 15 & $\begin{array}{l}\text { Política social y derechos } \\
\text { ciudadanos }\end{array}$ & 2 \\
\hline 16 & Vivienda & 0,25 & 16 & & \\
\hline
\end{tabular}


RLCS, Revista Latina de Comunicación Social, 76, 163-188

[Investigación] DOI: 10.4185/RLCS-2020-1442 | ISSN 1138-5820 | Año 2020

\begin{tabular}{|l|l|l|l|l|l|}
\hline \hline 17 & Política territorial & 0,25 & 17 & Cultura y lengua & 2 \\
\hline 18 & Industria y energía & 0,25 & 18 & PYMES & 1,76 \\
\hline 19 & - & - & 19 & Memoria histórica & 1,25 \\
\hline 20 & - & - & 20 & Inmigración & 1 \\
\hline 21 & - & - & 21 & Política estatal & 1 \\
\hline 22 & - & - & 22 & I+D+i & 0,5 \\
\hline 23 & - & - & 23 & Financiación autonómica & 0,5 \\
\hline 24 & - & - & 24 & Vivienda & 0,5 \\
\hline 25 & - & - & 25 & Otros & 0,25 \\
\hline
\end{tabular}

Fuente: elaboración propia.

El formato y el número de participantes (y una duración de casi dos horas y media) ha influido en la configuración de la agenda, muy diversa y amplia, en la que han destacado de forma notable los temas referentes a la propia intendencia de una campaña electoral (política de pactos, acusaciones, ideología, etc.), seguido del empleo (creación y precariedad) y de los servicios públicos de sanidad y educación. Destacan muy especialmente, la situación del territorio y población (5), el sector primario (7) y las infraestructuras (8) que definen una agenda mediática que conjuga problemas crónicos y los específicos de la Comunidad Autónoma. La política territorial ha estado presente en mayor medida que en otros territorios, con apelaciones (a través del issue de "Política territorial") a la unidad de España por parte de Ciudadanos, PP, PSOE y Vox. Estos últimos han intentado introducir temas como la inmigración, la memoria histórica y la corrupción, que encontró en Ciudadanos un aliado para situarlo en el puesto 11, de los más altos de España. Las elecciones las vencería finalmente el PSOE con mayoría absoluta.

\subsection{Elecciones en Castilla León y Castilla La Mancha}

La corporación privada Radio Televisión de Castilla y León (RTVCYL) fue la encargada de retransmitir el primer debate electoral celebrado entre los candidatos a la Presidencia de Castilla y León (de un total de dos) que enfrentó al popular Alfonso Fernández Mañueco, al socialista Luis Tudanca, al representante de Podemos, Pablo Fernández, y a Francisco Igea por parte de Ciudadanos (que, tras el resultado electoral, haría de nuevo presidente al conservador a pesar de la victoria del candidato sanchista). El formato estuvo dividido en cuatro bloques ("Despoblación y desarrollo rural"; "Economía y empleo"; "Fiscalidad"; "Regeneración democrática") con turnos de seis minutos, de los cuales uno se reservaba para una toma de posición y los siguientes cinco para un debate dirigido. Igualmente, los presidenciables contaron con una intervención inicial de un minuto y medio y una final de un minuto, destinada a apelar directamente a los ciudadanos.

A nivel temático, los bloques determinaron en gran medida las propuestas de los candidatos, que redundaron en sus propuestas en un formato de debate excesivamente largo y encorsetado. En general, se pudo detectar la preeminencia de los llamados problemas crónicos con presentaciones muy vagas y descriptivas (política económica, empleo y servicios públicos), además de dos elementos que lo diferenciaron del de otras comunidades autónomas. En primer lugar, el issue de la corrupción en un destacado quinto lugar (aupado, principalmente, en el bloque de "Regeneración democrática" y los sucesivos casos tras más de tres décadas del gobierno del Partido Popular); en segundo término, las apelaciones a la despoblación, al ser Castilla-León una de las regiones más azotadas de la llamada "España vaciada". Llama especialmente la atención la poca relevancia de la política social, el medio ambiente, la política territorial o la financiación autonómica. 
RLCS, Revista Latina de Comunicación Social, 76, 163-188

[Investigación] DOI: 10.4185/RLCS-2020-1442 | ISSN 1138-5820 | Año 2020

Tabla 6. Agendas temáticas Castilla León y Castilla La Mancha.

\begin{tabular}{|c|c|c|c|c|c|}
\hline \multicolumn{3}{|c|}{ CASTILLA LEÓN } & \multicolumn{3}{|c|}{ CASTILLA LA MANCHA } \\
\hline Rango & Tema & Puntuación & Rango & Tema & Puntuación \\
\hline 1 & Política económica & 7,75 & 1 & Servicios públicos & 13 \\
\hline 2 & Empleo & 4,5 & 2 & Campaña e ideología & 12,5 \\
\hline 3 & Servicios públicos & 4,25 & 3 & Política económica & 7 \\
\hline 4 & Política institucional & 4 & 4 & Sector primario & 5,5 \\
\hline 5 & Corrupción y regeneración & 4 & 5 & Empleo & 4,25 \\
\hline 6 & Población y territorio & 3 & 6 & Política estatal & 3,25 \\
\hline 7 & Campaña e ideología & 2,75 & 7 & $\begin{array}{l}\text { Política social y derechos } \\
\text { ciudadanos }\end{array}$ & 2,50 \\
\hline 8 & PYMES & 2,5 & 8 & Política institucional & 2,25 \\
\hline 9 & Igualdad & 2 & 9 & PYMES & 2 \\
\hline 10 & Política estatal & 1,5 & 10 & Financiación autonómica & 2 \\
\hline 11 & Colectivos minorizados & 1 & 11 & Medio ambiente & 1,75 \\
\hline 12 & $\begin{array}{l}\text { Política social y derechos } \\
\text { ciudadanos }\end{array}$ & 0,75 & 12 & Política territorial & 1,75 \\
\hline 13 & Industria y energía & 0,5 & 13 & Industria y energía & 1 \\
\hline 14 & $\mathrm{I}+\mathrm{D}+\mathrm{i}$ & 0,5 & 14 & Cultura y lengua & 1 \\
\hline 15 & Financiación autonómica & 0,5 & 15 & Igualdad & 0,5 \\
\hline 16 & Política territorial & 0,25 & 16 & Colectivos minorizados & 0,25 \\
\hline 17 & Medio Ambiente & 0,25 & 17 & Territorio y población & 0,25 \\
\hline 18 & Infraestructuras y transporte & 0,25 & 18 & Infraestructuras y transporte & 0,25 \\
\hline 19 & Sector primario & 0,25 & 19 & - & - \\
\hline
\end{tabular}

Fuente: elaboración propia.

La televisión pública de Castilla la Mancha (Castilla-La Mancha Media) fue la encargada de albergar, el día 20 de mayo, el debate entre los candidatos a la Presidencia de la Comunidad Autónoma, en la que participaron Emiliano García-Page (PSOE, que obtendría en la noche electoral mayoría absoluta), Paco Núñez (PP), José García Molina (Podemos), Carmen Picazo (Ciudadanos) y Daniel Arias (Vox). Su desarrollo (con un debate más largo de lo habitual) se estructuró en torno a cinco grandes bloques con cuatro minutos de intervención para cada candidato -en el que uno era para fijar postura y el resto de interpelaciones-, un minuto de intervención inicial, un minuto para los pactos y un minuto final apelando al voto. Los bloques, que determinaron en gran medida los temas o issues tratados, fueron los de "Empleo e industria", "Sanidad y Política Social", "Educación, cultura e igualdad"; "Agricultura, agua y medio ambiente" y "Política fiscal y financiación autonómica". En primera posición en rango se han situado los servicios públicos, seguido de las cuestiones referentes a la campaña (ideología, temas personales u otras dinámicas propias de la confrontación dialéctica), y en tercer término la política económica. Con una posición más centrada que la de sus homólogos socialistas, Emiliano García Page fue capaz de trasladar un discurso centrado en tres ejes: un carácter regionalista sin romper "la unidad nacional"; la introducción del tema de política estatal a su favor ya que "se enfrentó a Pedro Sánchez y a Mariano Rajoy por igual en defensa de los intereses de los castellanomanchegos"; finalmente, enmarcando constantemente a su rival Paco Núñez (PP) en la nefasta gestión de Cospedal. El resto de las temáticas han tenido un seguimiento desigual: PYMES y agravio territorial ( $\left.\mathrm{C}^{\prime} \mathrm{s}\right)$, Financiación autonómica (Podemos) y la defensa de la cultura tradicional (Vox) han asumido posiciones subsidiarias, con un medio ambiente (11) e igualdad (15) prácticamente desaparecidas.

\subsection{Elecciones en Baleares y Canarias}

El 15 de mayo se celebró en IB3 Televisió el debate electoral en las Islas Baleares que enfrentó a Gabriel Company (Partido Popular), Francina Armengol (PSOE), Juan Pedro Yllanes (Unidas 
Podemos), Marc Pérez-Ribas (Ciudadanos), Miquel Ensenyat (Més), Jaume Font (El Pi), Silvia Tur (Gent per Formentera) y Josep Castells (Més per Menorca). Con una ligera representación de voces progresistas por la forma jurídica que toman las coaliciones en Formentera y Menorca, durante el espacio televisivo hubo claramente dos bloques: los que apostaban por el cambio político con perspectiva conservadora ( $\mathrm{PP}, \mathrm{C}^{\prime} \mathrm{s}, \mathrm{El} \mathrm{Pi}$ ) y los actores políticos con vocación de continuidad del gobierno progresista. Las elecciones las ganaría la candidata socialista, que finalmente presidiría la Comunidad Autónoma.

Tabla 7. Agendas temáticas Baleares y Canarias.

\begin{tabular}{|l|l|l|l|l|l|}
\hline \multicolumn{2}{|c|}{ BALEARE } & \multicolumn{2}{c|}{ CANARIAS } \\
\hline Rango & \multicolumn{2}{|c|}{ Puntuación } & \multicolumn{2}{c|}{ Rango } & \multicolumn{2}{c|}{ Tema } & Puntuación \\
\hline 1 & Política económica & 13,25 & 1 & Servicios públicos & 13,5 \\
\hline 2 & Ideología y campaña & 13 & 2 & Campaña e ideología & 8 \\
\hline 3 & Servicios públicos & 8,75 & 3 & Vivienda & 5,5 \\
\hline 4 & Vivienda & 8 & 4 & Política económica & 5 \\
\hline 5 & Política institucional & 5 & 5 & Corrupción y regeneración & 3,75 \\
\hline 6 & $\begin{array}{l}\text { Política social y derechos } \\
\text { ciudadanos }\end{array}$ & 4,5 & 6 & Política territorial & 3,25 \\
\hline 7 & Turismo & 4,25 & 7 & $\begin{array}{l}\text { Política social y derechos } \\
\text { ciudadanos }\end{array}$ & 3 \\
\hline 8 & Medio ambiente & 3,75 & 8 & Empleo & 2,75 \\
\hline 9 & Infraestructura y transporte & 3,25 & 9 & Infraestructuras y transporte & 2,50 \\
\hline 10 & Empleo & 3 & 10 & Política estatal & 2,25 \\
\hline 11 & Colectivos minorizados & 2,25 & 11 & Cultura y lengua & 2,25 \\
\hline 12 & Política territorial & 2 & 12 & Política institucional & 1,75 \\
\hline 13 & Cultura y lengua & 1,75 & 13 & Territorio y población & 1,50 \\
\hline 14 & Igualdad & 1 & 14 & Turismo & 1,25 \\
\hline 15 & PYMES & 0,75 & 15 & Medio ambiente & 1,25 \\
\hline 16 & Territorio y población & 0,75 & 16 & Igualdad & 1 \\
\hline 17 & Política estatal & 0,5 & 17 & Deportes & 0,75 \\
\hline 18 & Financiación autonómica & 0,5 & 18 & PYMES & 0,5 \\
\hline 19 & I+D+1 & 0,5 & 19 & I+D+i & 0,25 \\
\hline 20 & Corrupción y regeneración & 0,5 & 20 & Colectivos minorizados & 0,25 \\
\hline 21 & - & - & 21 & Industria y energía & 0,25 \\
\hline 22 & - & & 22 & Inmigración & 0 \\
\hline & & & & \\
\hline
\end{tabular}

Fuente: elaboración propia.

A diferencia de otros territorios, en las Islas Baleares la agenda temática se ha construido de una forma particular: en el rango número 4, 7 y 8 se han situado problemas específicos de la Comunidad Autónoma, como son la vivienda, el turismo y el medio ambiente. El primero de ellos ligado principalmente a la subida derivada del precio de alquileres y escasez de vivienda pública; el segundo, sobre el modelo de turismo y las posibilidades de crecimiento; el último, medio ambiente, no tan ligado a la visión ideológica general del cambio climático, sino más bien inherente a la propia ordenación del territorio y a la presión urbanística. Situado en las tres primeras posiciones la recurrente política económica (subidas y bajas de impuestos) y servicios públicos (sanidad y educación), además de la autorreferencialidad de los candidatos: hablan de sí mismos, de sus partidos, de la ideología o de las coaliciones. La corrupción ocupa el último puesto en rango, desplomando la importancia que medios y políticos le dan al issue en los espacios electorales, con la política estatal en el puesto 14 (solamente dos referencias a Sánchez y Rajoy) y la financiación autonómica en el puesto 18. 
El día 23 de mayo y con 93 minutos de duración, el debate de las elecciones al Parlamento de Canarias en TVE-Canarias congregó a los principales candidatos a la Presidencia de la Comunidad Autónoma: Fernando Clavijo (Coalición Canaria); Ángel Torres (PSOE); Asier Gómez (PP); Noemía Santana (Si Podemos Canarias); Román Rodríguez (NC); Vidina Espino Ramírez (Ciudadanos). Se ha seleccionado este debate, y no el realizado en la Televisión Canaria, por entenderlo como más representativo, debido a la exclusión de Ciudadanos en este último. El resultado de las elecciones desplazaría a Coalición Canaria del poder, liderando el PSOE el nuevo ejecutivo con el apoyo de NC, Podemos y ASG. El debate se dividiría en seis bloques (Sanidad y Política Social; Empleo; Ordenación de Territorio, Vivienda y Obras Públicas; Educación; Pactos) con intervenciones iniciales de 1 minuto sin interrupciones por parte de los candidatos y otros dos a su libre disposición, durante las réplicas en los dos primeros bloques y uno en los dos siguientes. De igual forma, se dispuso un minuto de libre designación en el quinto apartado sobre pactos electorales y un minuto final. El debate estuvo caracterizado por un ataque de prácticamente todos los partidos a Coalición Canaria centrado en los ejes de mala gestión, regeneración democrática y corrupción (5), con bastante transversalidad interbloques y una agenda territorial volcada en la mala calidad de los servicios públicos y el alto precio de la vivienda. Es importante señalar la no introducción por parte del medio de comunicación de un bloque sobre turismo, una de las principales señas de identidad de la Comunidad Autónoma, así como la muy pequeña presencia de la igualdad entre hombres y mujeres (citado por PP, C'S y NC) o medio ambiente (solamente por NC).

\subsection{Elecciones en Madrid}

El debate de los candidatos a la Presidencia de la Comunidad de Madrid enfrentó a Isabel Díaz Ayuso (PP), Ángel Gabilondo (PSOE), Isabel Serra (Unidas Podemos), Ignacio Aguado (Ciudadanos) y Rocío Monasterio (Vox). No participó el candidato de Más Madrid, Iñigo Errejón, por ser considerada una formación de nueva creación por parte de la Junta Electoral Central (sin representación en la Asamblea Regional ni haber concurrido a otros procesos y haber obtenido un porcentaje de voto significativo, como en el caso de Vox). El resultado electoral acabó con una victoria del bloque conservador que, a través de un pacto de gobierno con Ciudadanos, y un acuerdo de investidura con Vox, haría presidenta a Díaz Ayuso. El debate, realizado en Telemadrid, estuvo organizado en cinco grandes bloques (Economía y Empleo; Sanidad y educación; Política social; Urbanismo, movilidad y medio ambiente; Pactos), con el conocido como "minuto de oro" final y una intervención inicial de cada candidato, a modo de presentación, que la propia televisión calificó como "minuto de plata". La novedad de este debate fue la estructura interna de cada bloque: dos o tres minutos por cada candidato, fijando primeramente una posición inicial a través de una pregunta del periodista y el resto del tiempo para el debate y la contraargumentación.

En general, la discusión asumió un marcado carácter ideológico (primera posición en rango), con dos bloques muy marcados, y la construcción de un marco discursivo por parte del PP y de Vox que contrapone el Madrid "liberal" o "de la libertad" y el "socialismo" o "las izquierdas totalitarias". Por su parte, el candidato de Ciudadanos, Ignacio Aguado, empleó una gran parte de su tiempo a atacar a Ángel Gabilondo a través de la introducción de temas como política económica (2) o recordando su gestión como Ministro de José Luis Rodríguez Zapatero ("política estatal"). En general, existe una agenda más estatalizada, con la introducción de temas como "seguridad", "inmigración" o "igualdad", más propias de las dinámicas del Estado. Llama la atención la escasa atención dada a la integridad territorial o al agravio comparativo en materia de financiación. 
Tabla 8. Agenda temática Madrid.

\begin{tabular}{|l|l|l|}
\hline \multicolumn{3}{|c|}{ MADRID } \\
\hline Rango & \multicolumn{1}{|c|}{ Tema } & Puntuac. \\
\hline 1 & Ideología y campaña & 16,25 \\
\hline 2 & Política económica & 7 \\
\hline 3 & $\begin{array}{l}\text { Política social y derechos } \\
\text { ciudadanos }\end{array}$ & 5 \\
\hline 4 & Vivienda & 4,5 \\
\hline 5 & Servicios públicos & 4,25 \\
\hline 6 & Infraestructuras y transporte & 4,25 \\
\hline 7 & Política estatal & 3,25 \\
\hline 8 & Corrupción y regeneración & 2 \\
\hline 9 & Inmigración & 1,50 \\
\hline 10 & Política territorial & 1,50 \\
\hline 11 & Igualdad & 1,25 \\
\hline 12 & Política institucional & 1,25 \\
\hline 13 & Seguridad & 1 \\
\hline 14 & Industria y energía & 1 \\
\hline 15 & Colectivos vulnerables & 0,75 \\
\hline 16 & PYMES & 0,75 \\
\hline 17 & Empleo & 0,5 \\
\hline
\end{tabular}

Fuente: elaboración propia.

\subsection{Viejos temas y nuevas discusiones: análisis y correlaciones}

La política económica ha protagonizado gran parte de las disputas entre candidatos situándose de forma mayoritaria entre el rango 1 y 3 , dimensionado por la estructura de los debates en bloques, en el que por lo menos uno estaba destinado a hablar sobre economía. Las propuestas han estado centradas en dos dimensiones. La primera, sobre la progresividad fiscal y la subida y bajada de impuestos en los tramos autonómicos, con los partidos de la derecha proponiendo una bajada generalizada que provocara más activación económica ("el dinero es más rentable en el bolsillo de los contribuyentes") y los de la izquierda (principalmente Podemos, confluencias y partidos nacionalistas) indicando la necesidad de subírselo a las rentas más altas para invertir en servicios públicos. En segundo lugar, en una dimensión más simbólica que roza lo ideológico, la disputa entre "dos modelos distintos", no solo en la competición interbloques, sino también presente en la intrabloques: el modelo que apuesta por la libertad económica y el que aboga por la intervención.

La política social, codificada en temas como "Servicios Públicos", "Política social y derechos ciudadanos", "Colectivos minorizados" o "Vivienda" ha tenido una presencia notable por dos hechos: primero, la lógica competencial que descentraliza su gestión en las Comunidades Autónomas y las sitúa como una de las prioridades de la agenda política; en segundo lugar, por su colocación por parte de las televisiones como "bloque" que orienta la estrategia de los candidatos y el centro de gravedad de los propios debates. Regiones como Cantabria, La Rioja, Aragón o Castilla la Mancha tienen un tema social liderando la clasificación, Canarias incluyó dos (primer y tercer puesto) y solamente en Valencia y Murcia no ocupan una de las tres primeras posiciones en rango.

El issue campaña e ideología (que agrega en periodo electoral a todas aquellas apelaciones propias de un contexto de confrontación, como temas personales del candidato, partidarios e ideológicos) se sitúa en todos los casos entre los rangos 1 y 6, con un carácter más marcado en las Comunidades Autónomas con más población urbana (Madrid y Valencia). En éstas las apelaciones a la "izquierda", a la igualdad y al "liberalismo" o libertad son mucho más habituales, con enfrentamientos que se acercan más al mundo de las ideas que al de las políticas públicas. En el presente issue se han codificado las propuestas postelectorales sobre coaliciones, por entenderse que forman parte de la 
intendencia de una campaña electoral. Los servicios públicos (sanidad y educación) han ocupado igualmente posiciones muy importantes en todos los debates electorales (1-5), dimensionado por unos bloques mediáticos específicos para este tema. Todos los candidatos han apostado por reforzar el carácter público de estos servicios, sin una diferencia sustancial entre ellos más allá de la apelación de los candidatos de Ciudadanos a ejercer la colaboración público-privada que en momentos también defendió el Partido Popular. Tanto PSOE como Podemos, en aquellas comunidades en dónde ejercía de oposición, han marcado sus líneas de actuación en este tema en algo más que la titularidad: listas de espera, precariedad laboral e infraestructuras educativas y sanitarias fueron sus principales argumentos. Finalmente, existen algunas Comunidades Autónomas que entre sus primeros temas posicionan aquellos con un especial interés para su región: infraestructuras (Cantabria); territorio y población (Extremadura); Castilla La Mancha (sector primario); Baleares, Canarias y Madrid (vivienda). Es importante recalcar la posición totalmente subsidiaria que tiene la inmigración (que en la dimensión simbólica funciona mucho más en la política estatal), que obtiene como mejor resultado el puesto 10 en Madrid (por las continuas referencias de Rocío Monasterio, de Vox).

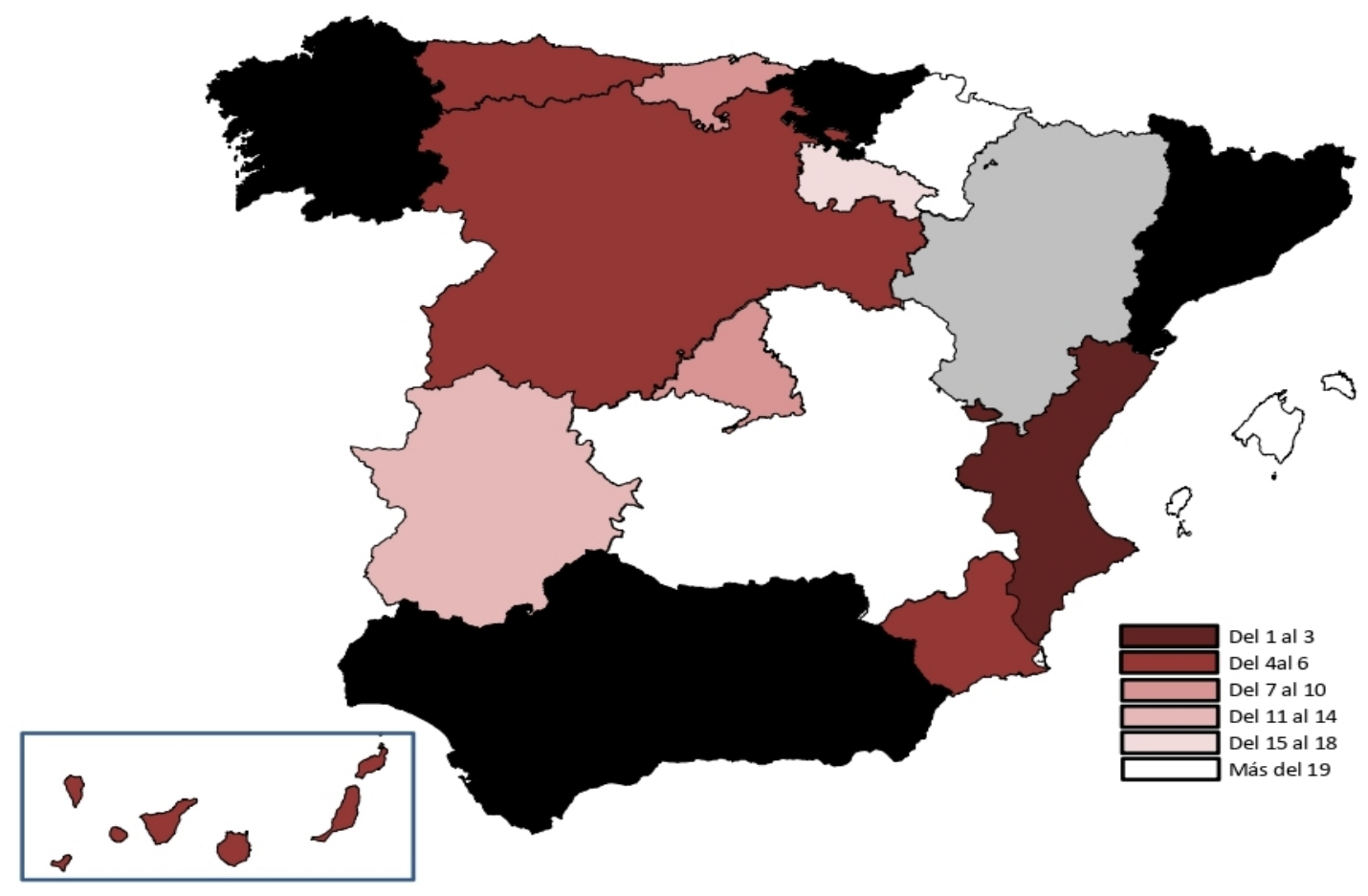

Imagen 2. La corrupción en agenda por Comunidades Autónomas.

Fuente: elaboración propia.

La corrupción ha estado presente, aunque de forma muy desigual. Este tema, con presencia continuada en la agenda mediática, en la política y en la opinión pública en el último lustro (CIS, $2019)^{2}$, ha tenido distinta repercusión en cada territorio: han sido Valencia (2), Asturias (5), Murcia (4), Castilla y León (5), Canarias (5) en dónde se ha situado en primeros puestos en rango vinculado principalmente al Partido Popular y a Coalición Canaria, con especial énfasis por parte de Podemos y de Compromís en Valencia, y muchas menos referencias por parte de Ciudadanos.

Por otra parte, los temas que han podido conformar una agenda propia de reivindicación de las Comunidades Autónomas, codificadas como "Política territorial" y "Financiación Autonómica", han estado prácticamente ausentes de los debates, con una reproducción de modelos de agenda estatal. El

\footnotetext{
${ }^{2}$ La corrupción comenzó a despuntar en la agenda pública a principios del año 2013, manteniéndose en niveles altos hasta la actualidad, aunque siempre con una tendencia a la baja.
} 
primero de ellos se ha situado entre los rangos 5 y 19, con puestos mayormente bajos, destacando la realidad navarra (5) y canaria (6) con una demanda destinada a reforzar los Estatutos de Autonomía y una tímida apelación a la cesión de competencias, sobre todo por los partidos nacionalistas o regionales. Por su parte, lo que en un primer momento se puede entender como un tema frecuente en los debates, como es la financiación autonómica, solo ha estado presente en el debate de la Comunidad Valenciana (6) y de nuevo en Navarra (4) de forma destacada, figurando en los últimos lugares en el resto (en muchas ocasiones en los cinco últimos lugares en rango). En esta categoría ("Política territorial") también se han codificado las referencias a la situación de Cataluña y a la integridad territorial, con una presencia muy escasa en los territorios, con las excepciones de Aragón por parte del candidato popular (4) y Extremadura por parte del socialista (10).

Tabla 9. Correlación $(N=18)$ a través del coeficiente de correlación de Spearman.

\begin{tabular}{|c|c|c|c|c|c|c|c|c|c|c|c|c|c|c|}
\hline & & Ast & Can & $\mathrm{Nav}$ & $\mathrm{LaR}$ & Ara & Val & Mur & Ext & $\mathrm{CL}$ & CLM & Bal & Canr & Madr \\
\hline Asturias & $\begin{array}{l}\text { Coeficiente de } \\
\text { correlación }\end{array}$ & 1,000 & & & & & & & & & & & & \\
\hline & Sig. (bilateral) & & & & & & & & & & & & & \\
\hline Cantabria & $\begin{array}{l}\text { Coeficiente de } \\
\text { correlación }\end{array}$ &, $740^{* *}$ & 1,000 & & & & & & & & & & & \\
\hline & Sig. (bilateral) &, 000 & & & & & & & & & & & & \\
\hline Navarra & $\begin{array}{l}\text { Coeficiente de } \\
\text { correlación }\end{array}$ & ,449 &, $657^{* *}$ & 1,000 & & & & & & & & & & \\
\hline & Sig. (bilateral) &, 062 &, 003 & & & & & & & & & & & \\
\hline La Rioja & $\begin{array}{l}\text { Coeficiente de } \\
\text { correlación }\end{array}$ & $684^{* *}$ &, $792^{* *}$ &, $548^{*}$ & 1,000 & & & & & & & & & \\
\hline & Sig. (bilateral) & ,002 &, 000 &, 019 & & & & & & & & & & \\
\hline Aragón & $\begin{array}{l}\text { Coeficiente de } \\
\text { correlación }\end{array}$ &, $505^{*}$ &, $676^{* *}$ &, $856^{* *}$ &, $680^{* *}$ & 1,000 & & & & & & & & \\
\hline & Sig. (bilateral) &, 033 &, 002 &, 000 & ,002 & & & & & & & & & \\
\hline Valencia & $\begin{array}{l}\text { Coeficiente de } \\
\text { correlación }\end{array}$ & ,395 &, $496^{*}$ &, $715^{* *}$ & ,311 &, $717^{* *}$ & 1,000 & & & & & & & \\
\hline & Sig. (bilateral) & ,104 &, 036 & ,001 & ,210 &, 001 & & & & & & & & \\
\hline Murcia & $\begin{array}{l}\text { Coeficiente de } \\
\text { correlación }\end{array}$ & , $488^{*}$ & ,418 & ,422 & ,391 &, $542^{*}$ &, $676^{* *}$ & 1,000 & & & & & & \\
\hline & Sig. (bilateral) &, 040 &, 084 & ,081 & ,108 &, 020 & ,002 & & & & & & & \\
\hline Extremad & $\begin{array}{l}\text { Coeficiente de } \\
\text { correlación }\end{array}$ &, $688^{* *}$ &, $604^{* *}$ &, 459 &, $812^{* *}$ &, $647^{* *}$ &, $513^{*}$ & , 457 & 1,000 & & & & & \\
\hline & Sig. (bilateral) &, 002 & ,008 & ,055 &, 000 &, 004 &, 030 & ,056 & & & & & & \\
\hline Cast. León & $\begin{array}{l}\text { Coeficiente de } \\
\text { correlación }\end{array}$ &, $562^{*}$ &, $595^{* *}$ & ,383 & ,437 &, $503^{*}$ &, $608^{* *}$ &, $604^{* *}$ &, $550^{*}$ & 1,000 & & & & \\
\hline & Sig. (bilateral) & ,015 & ,009 &, 117 &, 070 &, 034 & ,007 & ,008 & ,018 & & & & & \\
\hline C La Man & $\begin{array}{l}\text { Coeficiente de } \\
\text { correlación }\end{array}$ &, 315 & ,422 &, $496^{*}$ &, $631^{* *}$ &, $618^{* *}$ &, 323 & ,449 &, $531^{*}$ &, $503^{*}$ & 1,000 & & & \\
\hline & Sig. (bilateral) & ,203 &, 081 & ,036 &, 005 &, 006 & ,191 & ,062 & ,023 &, 034 & & & & \\
\hline Baleares & $\begin{array}{l}\text { Coeficiente de } \\
\text { correlación }\end{array}$ &, $558^{*}$ & ,437 &, $622^{* *}$ &, 451 &, $544^{*}$ &, 368 & ,424 & ,422 & ,317 & ,340 & 1,000 & & \\
\hline & Sig. (bilateral) & ,016 &, 070 & ,006 &, 060 &, 020 &, 132 & ,079 &, 081 & ,200 & ,168 & & & \\
\hline Canarias & $\begin{array}{l}\text { Coeficiente de } \\
\text { correlación }\end{array}$ &, $610^{* *}$ &, $542^{*}$ &, $573^{*}$ & ,331 &, $622^{* *}$ &, $558^{*}$ & ,467 &, 360 & ,370 & ,205 &, $715^{* *}$ & 1,000 & \\
\hline & Sig. (bilateral) & ,007 & ,020 & ,013 &, 179 & ,006 & ,016 &, 050 & , 142 & ,130 & ,414 & ,001 & & \\
\hline Madrid & $\begin{array}{l}\text { Coeficiente de } \\
\text { correlación }\end{array}$ & ,434 &, $517^{*}$ & ,455 & ,302 & ,465 & ,348 & ,199 & ,129 & , 170 & ,106 &, $620^{* *}$ &, $779^{* *}$ & 1,000 \\
\hline & Sig. (bilateral) & ,072 & ,028 & ,058 & ,223 & 052 & ,157 & ,428 & ,610 & 499 & ,675 & ,006 & ,000 & \\
\hline
\end{tabular}

** La correlación es significativa al nivel 0,01 (bilateral).

** La correlación es significativa al nivel 0,01 (bilateral).

Fuente: elaboración propia. 
Otros de los temas de carácter postmaterial que han entrado con fuerza en la agenda política y mediática estatal (igualdad y medio ambiente) no han tenido gran repercusión en los debates autonómicos, bien sea porque las televisiones han decidido no introducirlos como bloque específico o bien porque los partidos no los han considerado como una prioridad. Además, el enfoque que se ha dado ha sido muy distinto al que se realiza a nivel estatal. En el caso de la Igualdad (nos referimos principalmente a las políticas destinadas a combatir las desigualdades y violencias que sufre la mujer) su situación ha sido inferior, destacando el puesto número 9 que ocupó en Castilla y León. Las mayores referencias las han realizado los candidatos y candidatas del PSOE, aunque también Podemos ("revolución morada"); se han incluido las constantes referencias de Vox a lo que califican como "ideología de género" en los debates en los que han participado, sin mucho éxito de reproducción en las réplicas y sucesivas contrarréplicas.

Por su parte, el tema "Medio Ambiente" ha tenido una mejor posición relativa (ocupando el puesto número 3 en Murcia y número 8 en Baleares), aunque, lejos de realizar una reflexión sobre la transición ecológica, modelo energético o cambio climático, las casuísticas locales han copado este issue: en Murcia la situación del Mar Menor y, en el resto, pequeños problemas de contaminación o desarrollo local sostenible.

Como se puede observar en la tabla 9, fruto de relacionar las agendas temáticas de los debates en cada uno de los territorios a través del coeficiente de correlación de Spearman, existen varias correlaciones que obtienen un alto nivel de significatividad estadística, algunas de ellas con altos niveles de intensidad $(>0,70 \mathrm{y}<0,90)$. La dimensión territorial (norte/sur, mediterráneo/cantábrico o insularidad) es en España una circunstancia que solo determina una alta correlación de la agenda temática en algunos casos, con correspondencias significativas entre territorios limítrofes, como son Aragón y Navarra (,856**), Cantabria y La Rioja (792**) o Asturias y Cantabria ( 740**), a pesar de encontrar relaciones altas entre Comunidades Autónomas alejadas, como pueden ser La Rioja y Extremadura $\left(0,812^{* *}\right)$ o entre Murcia y Castilla León $\left(, 608^{* *}\right)$. Otro criterio de territorialidad a tener en cuenta tiene que ver con las características de la insularidad, tal y como muestra la relación significativa al nivel $0,01\left(, 715^{* *}\right)$ entre Canarias y las Islas Baleares, con unos problemas comunes que se trasladan en los debates electorales, como puede ser el acceso a la vivienda, el turismo o el colapso de los servicios públicos.

La riqueza o pobreza de una región determina, pero de forma muy limitada, la prioridad que medios de comunicación y políticos dan a determinados temas. En función del PIB per cápita (INE, 2019a) existen mayores niveles de correlación entre las Comunidades Autónomas más ricas (Navarra, Aragón, La Rioja y Baleares), ya que, a excepción de una, todas tienen un nivel de significatividad con una intensidad moderada o alta. No ocurre lo mismo con las regiones más pobres, con resultados que non son estadísticamente relevantes. La densidad de población (INE, 2019b) también es un criterio que determina mayores niveles de significatividad. Las tres Comunidades Autónomas más densamente pobladas (Madrid, Baleares y Canarias) al igual que las que tienen menor densidad de población (Castilla León, Castilla La Mancha, Aragón y Extremadura) muestran altos niveles de correlación en la relación de temas en agenda, destacando la que se da entre Madrid y Canarias $\left(779^{* *}\right)$, cuestión que no ocurre si aplicamos el índice de envejecimiento (INE, 2019c)

La tasa de desempleo (INE, 2019d) tampoco parece un factor que determine, en primera instancia, mayores niveles de correlación: si bien se dan niveles moderados y altos de correlación entre tres de las cuatro regiones con menores niveles de desempleo (Cantabria, La Rioja y Navarra), no se da con la cuarta (Baleares) ni tampoco entre las Comunidades con más paro. Por el lado contrario, las agendas agregadas por Comunidades Autónomas en función del peso del sector económico (INE, 
2019e) encuentran, en todos los casos, altos índices de correlación: Murcia, Extremadura y Aragón (sector primario); La Rioja, Aragón y Navarra (industria); Madrid, Baleares y Canarias (servicios).

Finalmente, sobre la conformación de gobiernos durante el desarrollo de la legislatura (2015-2019), bien sea en solitario o en coalición, no existe una tendencia a construir agendas comunes cuando los socialistas o populares asumen la presidencia del ejecutivo, aunque si cuando un partido regionalista o nacionalista lo hace: así pasó en Cantabria con el PRC, en Navarra con Geroa Bai o en Canarias con CC $\left(, 657^{* *} ;, 542^{*} ;, 573^{*}\right)$, así como con la presencia en la vicepresidencia o consejerías, como Compromís en Valencia o la Chunta Aragonesista en Aragón, (496*, 715**, 558*; ,505*, ,856**, , $\left.622^{* *}\right)$ con una relación entre ellas del, $717^{* *}$. Es importante determinar la relación que este hecho tienen con la construcción que se ha producido en España de sistemas de partidos diferenciados en los diferentes territorios, fruto de la fortaleza e importancia, entre otras cuestiones, de los partidos de ámbito no estatal.

\section{Conclusiones y discusión}

La presente investigación ha abordado por primera vez, desde el amplio ámbito epistemológico de la comunicación política y dentro de un escenario de competición como es el de los debates electorales, las agendas territoriales españolas a través de un análisis sincrónico, cumpliendo pues con el objetivo principal (OP). En general, como primera conclusión (o1) y dentro de la categorización clásica (Zuluaga, \& Morales, 2017), se puede decir que los issues crónicos (política económica, servicios públicos y empleo) ocupan las primeras posiciones en rango en la mayor parte de las Comunidades Autónomas, sumándosele el de "Ideología y campaña", propio de los contextos electorales y coincidiendo con una gran parte de estudios de la agenda española. Esto es debido a una dimensión normalizada que no ocurría en la última década de la política española, con una agenda alterada fruto de la crisis económica (López-López, 2018). Igualmente, las decisiones sobre la organización de los debates han desplazado a los problemas intermitentes (inmigración), a los coyunturales (corrupción) o a los nuevos (feminismo o medio ambiente) a posiciones subsidiarias (o2). Llama poderosamente la atención el caso de la corrupción (P1), que de ocupar posiciones muy importantes en la agenda política y en la cobertura mediática (Palau, \& Davesa, 2013; Chavero 2012), pasa a un segundo plano.

La ideología ha estado presente (P2), con un carácter marcado en las regiones más urbanas, como Madrid, aunque no ha sido determinante en la construcción de la agenda. Lo "liberal", por una parte, y "la izquierda" por la otra, han sucumbido ante la realidad político-administrativa y los problemas de gestión de las regiones, además de la dinámica mediática impuesta por los medios de comunicación: el continente ha influido en el contenido. En este sentido, las estrategias han ido más encaminadas, por una parte, a subir en rango la política económica y el empleo por parte de la derecha; por la otra, a visibilizar la política social y el cuidado de los servicios públicos por parte de la izquierda, generando compartimentos estancos y poca dinámica de competición interbloques. En este contexto, en los debates en los que ha participado Vox (un total de seis) ha sido incapaz de introducir los problemas coyunturales o intermitentes que le podrían haber dado protagonismo (inmigración o seguridad), por considerarse exclusivos de la agenda estatal y, por lo tanto, manifestándose incapaz de generar alguna alteración en las agendas como se puede comprobar comparando los debates en los que ha participado y en los que no (P3). Por ello se puede concluir que la extrema derecha no ha marcado la agenda de temas sobre los que se discute en las Comunidades Autónomas.

Por otra parte, se ha visto que, contrariamente a lo que se pudiera creer, la agenda estatal (medios y partidos), salvo en Madrid, no tiene una influencia todopoderosa sobre la dinámica regional. Ejemplo 
de ello es la ausencia prácticamente total de Cataluña (P4) en los debates, con la excepción de Aragón (como se puede observar en la posición en rango de la política estatal y territorial). Lo determinante es saber que parte de esto hecho es consecuencia de las estrategias de los partidos o de la propia organización del debate.

Sobre las circunstancias que influyen en la configuración de agendas análogas, los factores económicos y de proximidad no determinan unos mayores niveles de correlación (H1). Por proximidad sí en el norte, pero no el sur (dónde no funciona la llamada "transferencia de relevancia"); si entre las ricas, pero no entre las pobres, y sin que la tasa de desempleo sea relevante. Ni tampoco la existencia de un mismo partido en el gobierno (H2): los gobiernos socialistas o populares no generan agendas comunes entre ellos ni distintas a la de sus contrincantes. Aunque en este último caso existe una excepción: la presencia de partidos políticos nacionalistas o regionalistas en el gobierno tiende a generar problemas compartidos entre sus respectivos territorios.

En definitiva, este trabajo, de carácter iniciático, debe ser discutido con futuras investigaciones que analicen y comparen la construcción de las agendas territoriales en función de lo siguiente: a) del contenido de los medios de comunicación fuera del ámbito exclusivamente electoral; b) de la agenda de sus actores políticos; c) de los problemas que la ciudadanía entiende como más relevantes en las distintas Comunidades Autónomas.

\section{Referencias bibliográficas}

Barreiro Rivas, X. L., Pereira López, M. e Hípola G. G. (2015). Los efectos sobre el voto de la campaña electoral en las elecciones europeas de 2014 en España. Revista Española de Ciencia Política, (39), 67-93.

Benoit, W. L. \& Hansen, G. J. (2001). Presidential debate questions and the public agenda. Communication Quarterly, 49(2), 130-141.

Bouza, F. (2004). El área de impacto de la Comunicación Política: la ciudadanía ante el discurso público. International Review of Sociology_Revue Internationale de Sociologie, 14(2), 245-259.

Bouza, F. y González, J. J. (2009). Razones del voto en la España democrática.1977-2008. Los Libros de la Catarata.

Campo Vidal, M. (2017). La cara oculta de los debates electorales. Arpa Editores.

Chavero, P. (2012). La corrupción política en los medios de comunicación españoles: un estudio del caso Gürtel (2008-2011). Circunstancia Revista de Ciencias Sociales del IUIOG, 10(29), 1-6.

CIS (2019). Tres problemas principales que existen actualmente en España. Centro de Investigaciones Sociológicas. https://bit.ly/2QeR7nQ

Dearing, J. \& Rogers, E. (1996). Agenda-setting. Communication Concepts 6. SAGE Publications.

García Luengo, Ó. (2011). Debates electorales en televisión: una aproximación preliminar a sus efectos inmediatos. Revista Española de Ciencia Política, (25), 81-96.

García Marín, J. (2015). La cobertura mediática de los debates electorales en España. Revista española de ciencia política, (38), 135-161. 
González, J. J. y Chavero, P. (2013). Variantes del negativismo informativo en un contexto de crisis global: la evaluación de los actores políticos y su interrelación. En Crespo, I. (Dir.). Partidos, medios y electores en procesos de cambio. Las elecciones generales españolas de 2011. Tirant Humanidades.

Harder, R. A., Sevenans, J., \& Van Aelst, P. (2017). Intermedia agenda setting in the social media age: How traditional players dominate the news agenda in election times. The International Journal of Press/Politics, 22(3), 275-293.

Herranz-Rubio, C. (2019). La producción científica sobre debates electorales en España: Análisis bibliométrico (1993-2018). Revista Mediterránea de Comunicación, (11), 1.

Humanes. M. L. (2012). El efecto agenda sobre los temas de campaña en las elecciones generales de 2008. AdComunica. Revista Científica de Estrategias, Tendencias e Innovación en Comunicación, (3), 191-207.

INE (2019a). Producto interior Bruto per cápita 2019. Instituto Nacional de Estadística. Recuperado de https://bit.ly/32Avj8S

INE (2019b). Densidad de población España 2019. Instituto Nacional de Estadística. Recuperado de https://bit.ly/33BFZFu

INE (2019c). Índice de envejecimiento España 2019. Instituto Nacional de Estadística. Recuperado de https://bit.ly/2X1 yipz

INE (2019d). Encuesta de Población Activa 2019. Instituto Nacional de Estadística. Recuperado de https://bit.ly/2K $7 \mathrm{wCpn}$

INE (2019e). Ocupación por sector económico 2019. Instituto Nacional de Estadística. Recuperado de https://bit.ly/33xUZo5

Iyengar, S. (1991). Is Anyone Responsible? How Television Frames Political Issues. The University of Chicago Press.

Jamieson, K. H., \& Campbell, K. K. (1994). The interplay of influence. News, advertising politics and the mass media. Wadsworth.

Lledó Callejón, P. (2011). La influencia de los debates electorales sobre la decisión de voto: el caso de mayo de 1993 en España. Revista Española de Ciencia Política, (6), 143-170.

López-Escobar, E., Llamas, J. P. y Rey Lennon, F. (1996). La agenda entre los medios: primero y segundo nivel. Comunicación y sociedad, 9(1\&2), 67-89.

López-García, G., Llorca-Abad, G., Valera-Ordaz, L. y Peris-Blanes, A. (2018). Los debates electorales, ¿el último reducto frente la mediatización? Un estudio de caso de las elecciones generales españolas de 2015. Palabra Clave, 21(3), 772-797.

López-López, P. C. (2018). Opinión Pública en el Reino de España: agenda de problemas y sistema de partidos en la poscrisis. En M. L. Paredes Nuevos escenarios de la comunicación: retos y convergencias. Centro Publicaciones PUCE. 
López-López, P. C. y Vásquez-González, J. (2018). Agenda temática y Twitter: elecciones presidenciales en América Latina durante el período 2015-2017. El profesional de la información, 27(6), 1204-1214.

López-López, P. C. y Oñate, P. (2019). De la videopolítica a la ciberpolítica: debate entre candidatos y televisiones en cinco elecciones presidenciales. El profesional de la información, 28(5).

López-López, P. C., Puentes-Rivera, I., Mila-Maldonado, A. \& Oñate, P. (2019). Axenda dixital e política no debate presidencial das eleccións brasileiras do ano 2018. En: IV Simposio Internacional sobre Gestión de la Comunicación, Porto, XESCOM.

Mayer, W. (1996). In Defense of Negative Campaigning. Political Science Quarterly, (111), 437-455.

McCombs, M. (2018). Setting the agenda: Mass media and public opinión. John Wiley \& Sons.

McCombs, M. \& Shaw, D (1972). The agenda setting function of mass media. The Public Opinion Quarterly, 36(2), pp. 176-187.

McKinney, M.S. \& Carlin, DB (2004). Political campaign debates. In Kaid, L. (Eds.) Handbook of political communication research, (pp. 221-252). Routledge.

Palau, A. y Davesa, F. (2013). El impacto de la cobertura mediática de la corrupción en la opinión pública española. Revista Española de Investigaciones Sociológicas, 144(1), 97-124.

Pérez Curiel, C. y Lancharro Montiel, M. I. (2017). Las estrategias de comunicación de Podemos y Ciudadanos en los debates electorales. Una aproximación mediante análisis de contenido: el debate de Atresmedia TV como estudio de caso. Razón y Palabra, (99), 589-615.

Reguera, M. G. y Rodal, A. B. (2018). Influencia y repercusión mediática de los debates "cara a cara" celebrados ante las elecciones generales de 2008 en España: José Luis Rodríguez Zapatero (PSOE) vs Mariano Rajoy (PP). Vivat Academia, (141), 139-154.

Saavedra-Llamas, M. y Rodríguez- Fernández, J. (2018). Las cadenas de televisión españolas frente al debate del 13J: estrategias de programación y audiencia social. Fonseca, Journal of Communication, (17), 125-136.

Swanson, D. (1995). El campo de Comunicación Política. La democracia centrada en los medios. En Muñoz-Alonso, A. y Rospir, J. I. (Ed.) Comunicación Política. Editorial Universitas.

Téllez Morales, N. M. (2009). Temas, encuadres y función discursiva en los debates electorales de México, España y Estados Unidos (Doctoral dissertation). Tesis de Maestría en Ciencias con Especialidad en Comunicación, Instituto Tecnológico y de Estudios Superiores de Monterrey, Campus Monterrey, México.

Weaver, D. H. (1997). Canalización mediática (“agenda-setting”) y elecciones en Estados Unidos. CIC. Cuadernos de Información y Comunicación, (3), 229-241.

Yang, X., Chen, B. C., Maity, M. \& Ferrara, E. (2016, November). Social politics: Agenda setting and political communication on social media. In International Conference on Social Informatics (pp. 330-344). Springer. 
Zuluaga, M. L. A. y Morales, G. R. (2017). La agenda pública en sus teorías y aproximaciones metodológicas. Una clasificación alternativa. Revista Enfoques: Ciencia Política y Administración Pública, 15(26), 13-35.

\section{AUTORES:}

\section{Paulo Carlos López-López}

Doctor por la Universidad de Santiago de Compostela con una tesis sobre comunicación y procesos electorales. Docente e investigador del Departamento de Ciencia Política e Socioloxía, pertenece a la Red Internacional de Investigación de Gestión de la Comunicación. Posee el Diploma de Estudios Avanzados en el Programa de Doctorado Comunicación y Periodismo de la USC. Licenciado en Periodismo en la rama de periodismo electrónico y Licenciado en Ciencias Políticas y de la Administración en la rama de Relaciones Internacionales por la misma Universidad. Tiene un curso de Formación Continua en Periodismo Especializado en Información Política. Posee más de medio ciento de artículos científicos publicados, participando en más de 30 congresos nacionales e internacionales. Miembro del Consejo Editorial de la Revista Internacional de Comunicación y Desarrollo, ha sido revisor en y ha formado parte de comités científicos de más de una decena de publicaciones. Experiencia laboral en campañas electorales, comunicación organizacional, gabinete de prensa y gestión parlamentaria. Fue director del Grupo de Investigación Medios, Tecnologías Aplicadas y Comunicación de la Pontificia Universidad Católica del Ecuador, obteniendo en su segundo año la categoría A, la máxima otorgada por la institución, coordinando una Maestría en Comunicación Política. Ha realizado estancias posdoctorales en universidades argentina y chilenas. Premio Drago 2019 por un estudio sobre transparencia.

paulocarlos.lopez@,usc.es

\section{Índice H: 5}

Orcid ID: http://orcid.org/0000-0002-8101-7976

Google Scholar: https://scholar.google.com/citations?user=VzvLbo4AAAAJ\&hl=en

\section{Palmira Chavero Ramírez}

Palmira Chavero Ramírez (Monesterio, Badajoz, 1983) es doctora en Ciencias de la Comunicación y Sociología por la Universidad Complutense de Madrid (España) en 2012; Licenciada en Periodismo por la misma universidad. Es investigadora del equipo de investigación Agenda y Voto y del Grupo de Investigación en Gobierno, Administración y Políticas Públicas (GIGAPP). Ha impartido clases en la Universidad Complutense de Madrid (España), el Instituto Universitario de Investigación Ortega y Gasset (España) y ha sido coordinadora del Laboratorio de Comunicación y Derechos en Ecuador (IAEN). Es profesora titular e investigadora en la Facultad Latinoamericana de Ciencias Sociales (FLACSO) en Ecuador, en el departamento de Estudios Internacionales y Comunicación. Es coordinadora de la Maestría de investigación en Comunicación y Opinión Pública. Es miembro de comités científicos de revistas académicas y revisora en revistas científicas internacionales. Es directora de FLACSO Radio. Sus líneas de trabajo son la Comunicación Política y Opinión Pública. Estudia la relación entre los medios de comunicación (y las nuevas herramientas comunicacionales) y los distintos actores de la esfera pública, en especial los del sistema político y los ciudadanos. En 2011 recibió el "I Premio Jóvenes Investigadores Joan Prats", concedido por Gigapp y el Instituto Universitario de Investigación Ortega y Gasset. Coautora de más de una decena de libros, de artículos en revistas científicas especializadas y de numerosas conferencias y ponencias en congresos internacionales. Ha trabajado como periodista durante más de diez años y es colaboradora en programas de análisis en los medios ecuatorianos; en 2008 recibió el Premio Periodismo 8 de marzo. pchavero@flacso.edu.ec

Orcid ID: https://orcid.org/0000-0001-8310-3600

Google Scholar: https://scholar.google.com.ec/citations?user=exkvCAoAAAAJ\&hl=es 


\section{María Pereira López}

Universidad de Santiago de Compostela. Tesis "Modelos de construcción de indicadores para la evaluación de los servicios públicos: definición y funcionamiento del índice de cobertura de servicios" (2013), tesis protegida por derechos de propiedad intelectual, Premio Extraordinario de Doctorado y Primer accésit del Premio de Tesis doctorales del INAP. Profesora de Ciencia Política en la USC y miembro del Equipo de Investigaciones Políticas de la USC, catalogado como Grupo de Referencia Competitiva por la Xunta de Galicia. Posee el Diploma de Estudios Avanzados en el Programa de Doctorado Procesos Políticos Contemporáneos de la USC y las titulaciones de Máster Oficial en Técnicas Estadísticas y Máster Propio en Marketing Político: Estrategias y Actores, ambos por la citada universidad. Licenciada en Ciencias Políticas y de la Administración por la USC. Tiene una amplia formación metodológica, con la realización de diferentes cursos en el ámbito estadístico y la neurofisiología. Posee un amplio número de artículos publicados en revistas científicas de impacto, así como comunicaciones en congresos nacionales e internacionales. Es Vicesecretaria de la Revista de Investigaciones Políticas y Sociológicas (RIPS) y Secretaria de la Revista MARCO. Marketing y Comunicación. Experiencia laboral en campañas electorales, comunicación organizacional, gabinete de prensa y gestión parlamentaria. Trabajó como consultora senior en varias consultoras de ámbito político y comunicativo y fue Jefa de Gabinete de la Secretaría de Análisis y Proyección de la Xunta de Galicia durante 2006-2009.

maria.pereira.1opez@usc.es

Orcid ID: https://orcid.org/0000-0002-2802-9396 